\title{
Revisión y ampliación del catálogo sísmico del noroeste de la Península Ibérica previo a 1755 y sus implicaciones en la actividad intraplaca
}

\section{Review and extension of the seismic catalogue in the northwest of the Iberian Peninsula before 1755 and their implications for the intraplate activity}

\author{
C. Crespo-Martín ${ }^{1}$, F. Martín-González ${ }^{1}$, G. Lozano ${ }^{1}$ \\ ${ }^{1}$ Área de Geología. ESCET. Universidad Rey Juan Carlos. C/ Tulipán, s/n. Móstoles, 28933 Madrid (Spain). Email: fidel. \\ martin@urjc.es; cristina.crespo@urjc.es. ORCID ID: https://orcid.org/0000-0002-8755-9784, https://orcid.org/0000-0002- \\ 4184-4088, https://orcid.org/0000-0002-5239-1846
}

\section{RESUMEN}

La base de los estudios de peligrosidad sísmica es disponer de catálogos sísmicos lo más completos posible. En regiones intraplaca, caracterizadas por largos periodos de recurrencia entre terremotos, es esencial obtener un catálogo sísmico con un extenso intervalo temporal. El noroeste de la Península Ibérica (Galicia, Asturias, Cantabria, Castilla y Leon y norte de Portugal) se ha considerado tradicionalmente una zona intraplaca sísmicamente estable, ya que se encuentra alejada de los bordes de placa sísmicamente activos. Sin embargo, crisis sísmicas como las Sarria-Triacastela-Becerreá (Lugo) (1995 y 1997; con eventos de magnitud hasta 5.3) ponen de manisfiesto en esta región un potencial sismogénico de magnitud moderada. En este trabajo se realiza una revisión y ampliación del catálogo sísmico de esta región previo a 1755 (periodo peor documentado del catálogo sísmico), con el objetivo de caracterizar esta sismicidad intraplaca y mejorar la completitud con un nuevo catálogo para el NO peninsular y así poder reconocer si la sismicidad reciente y posterior a 1755 es anómala o si, por el contrario, es característica de esta región. Para ello, se tomó como base el catálogo sísmico oficial español del Instituto Geográfico Nacional (IGN), que es la agencia responsable de la red y alerta sísmica. Se han buscado las fuentes documentales primarias de los terremotos descritos en dicho catálogo, para el margen espacial y temporal considerado, y se han revisado parámetros como la localización, fecha y zonas geográficas afectadas por el terremoto. En este catálogo a los 13 terremotos incluidos por el IGN, se han añadido 10 del catálogo de Ces Fernández (2015) y 4 nuevos, ampliando así el catálogo hasta los 27 terremotos. Tras revisar las fuentes se han modificado: 6 parámetros de fechas, 8 localizaciones y 10 zonas geográficas donde se sintió el sismo. Posteriormente ha sido posible calcular la intensidad de 18 de estos terremotos con dos escalas macrosísmicas (EMS-98 y ESI-07). En este nuevo catálogo las intensidades calculadas se encuentran entre IV y X en EMS-98 y entre VII y XI en la ESI07, es decir incluyen eventos de mayor o igual intensidad que los ocurridos después de 1755, que no han sobrepasado la intensidad VI o VII como ocurrió en la crisis de Sarria-Triacastela-Becerreá (Lugo) de 1997. Además, la distribución geográfica de los eventos anteriores a 1755 es similar a los ocurridos posteriormente. Todo ello indicaría que la sismicidad actual y posterior a 1755 no sería una anomalía de la tendencia de la región. En el futuro,

Recibido el 14 de diciembre de 2017; Aceptado el 19 de octubre de 2018; Publicado online el 28 de noviembre de 2018

Citation / Cómo citar este artículo: Crespo-Martín, C. et al. (2018). Revisión y ampliación del catálogo sísmico del noroeste de la Península Ibérica previo a 1755 y sus implicaciones en la actividad intraplaca. Estudios Geológicos 74(2): e085. https://doi.org/10.3989/ egeol.43083.477

Copyright: ( 2018 CSIC. Este es un artículo de acceso abierto distribuido bajo los términos de la licencia de uso y distribución Creative Commons Reconocimiento 4.0 Internacional (CC BY 4.0) 
para seguir ampliando el catálogo sísmico de esta región, sería necesario integrar estudios multidisciplinares de sismicidad histórica e instrumental y paleosismología, prestando atención a fallas que puedan ser activas, bajo el régimen tectónico actual.

Palabras clave: Terremotos históricos; intensidad macrosísmica, Galicia; Portugal; Castilla y León; Asturias; Cantabria; España.

\section{ABSTRACT}

The basis of the seismic hazard assessments is a seismic catalogue as complete as possible. In intraplate regions, it is essential to compile a catalogue covering a wide temporal interval due to the long recurrence periods between large earthquakes. The northwest of the Iberian Peninsula (Galicia, Asturias, Cantabria, Castilla y León and north of Portugal) is an intraplate region, which was considered seismically stable in the past, because it is far away from the seismically active plate boundaries. Nevertheless, some seismic crisises such as in SarriaTriacastela-Becerreá (Lugo) (1995 y 1997; maximum earthquake of magnitude 5.3) expose a moderate seismic activity in this region. In this paper a revision and enhancement of the seismic catalogue prior to 1755 (the worst studied period) is carried out, with the aim of characterizing this intraplate seismicity and to recognize if the seismicity after 1755 is anomalous in this region. For this purpose, we have based on the Spanish official seismic catalogue of the Instituto Geográfico Nacional (IGN), the agency responsible for the seismic network and warning. The research was first carried out for the original sources of the earthquakes described in this catalogue, in order to review and assess possible errors in the epicentral location, date or geographical areas affected by the earthquake. In addition to the 13 IGN catalogued earthquakes, 10 from the Ces Fernández (2015) catalogue and 4 new ones have been included, generating a new catalogue with 27 events. Following a review of the data sources, we modified 6 date parameters, 8 locations and 10 geographical areas where the earthquake was felt. Subsequently, the intensity of 18 earthquakes on two macro-seismic scales (EMS-98 and ESI-07) has been estimated. The resulting EMS-98 values range from IV to $X$ and from VII to XI in ESI-07, similar or even higher than those ocurring after 1755, which have not surpassed intensity VI or VII, as in the crisis of Sarria-Triacastela-Becerreá (Lugo) of 1997. Moreover, the geographical distribution of the events is similar before and after 1755. Taking altogether, such informations indicate that the actual seismicity and the seismicity after 1755 is not an anomalous phenomenon. This paper highlights the necessity of having a seismic catalogue as complete as possible, which should be extended using a multidisciplinary integration of historical and instrumental seismicity and paleosismological studies. For this reason, future studies of active tectonics and paleosismicity should pay attention to seismic faults that may be active under the current tectonic regime.

Keywords: historical earthquakes; macroseismic intensity; Galicia; Portugal; Castilla y León; Asturias; Cantabria; Spain.

\section{Introducción}

Para elaborar los estudios de riesgo sísmico, necesarios para mitigar las futuras pérdidas por terremotos, es imprescindible conocer la sismicidad que afectó a una región en el pasado. Obtener un catálogo sísmico más completo y que cubra un periodo de tiempo lo más amplio posible permite conocer y caracterizar mejor cómo es la intensidad o la recurrencia de los terremotos en esa región. Una combinación multidisciplinar de estudios históricos, paleosismológicos y de registros instrumentales puede permitir ampliar este catálogo y proporcionar información valiosa de las fallas sismogénicas, la localización y recurrencia de los terremotos y los efectos socioeconómicos que pueden generar en una región (p. ej. Mallet, 1862; Martínez Solares \& Mezcua, 2002; Michetti et al., 2007; Rajendran et al., 2013; Korjenkov \& Mazor, 2013; Mackey \& Quigley, 2014; González,
2017; Martín-González, 2018). La investigación de terremotos con datos históricos permite ampliar el periodo temporal del catálogo instrumental y es especialmente necesaria para complementar la información geológica, sobre todo en regiones donde existen importantes dificultades para estudiar las fuentes sísmicas o los periodos de recurrencia son muy grandes. Entre los inconvenientes para el estudio de las fuentes sísmicas se pueden destacar que se traten de fallas ciegas, que las fallas no presenten rupturas en superficie debido a enterramiento posterior, erosión y/o destrucción por actividad humana, o que sean terremotos de magnitudes moderadas $(M<6)$ que no generen importantes efectos geomorfológicos en la región (p. ej. Gasperini et al., 1999; Martín-González, 2009; Villamor et al., 2012; Martín-González et al., 2012; Mackey \& Quigley, 2014).

Los catálogos sísmicos incorporan información sobre terremotos pasados ocurridos en una región, la 
cual puede obtenerse, entre otros medios, mediante el estudio de sus narraciones en documentos históricos (p. ej. Mallet, 1862; Martínez Solares \& Mezcua, 2002; Galadini et al., 2006; Guidoboni \& Ebel, 2009; Ces Fernández, 2015; Ferrão et al., 2016; González, 2017; Udías, 2017). Esta información de los efectos y daños, junto con la manera en que la población sintió el terremoto, se han utilizado en muchos casos para hacer estimaciones de parámetros del sismo como la fecha, la localización, la profundidad focal, la intensidad y la falla sismogénica. Toda esta información es crucial para evaluar la peligrosidad sísmica y establecer los requisitos de construcción sismorresistente (Galadini et al., 2006; Comité Européen de Normalisation, 2004). Es especialmente importante reevaluar la peligrosidad sísmica a largo plazo en infraestructuras críticas, como centrales nucleares, ya que se les exige resistir terremotos con periodos de recurrencia muy largos (IAEA, 2010; 2015).

Los catálogos sísmicos actuales son fruto del trabajo de diferentes generaciones de investigadores. El conocimiento de la evolución de los catálogos es esencial para entender los catálogos actuales, ya que la información contenida en los antiguos se utiliza como base en los nuevos y sobre ellos se incorporan, actualizan o modifican nuevos trabajos (Guidoboni \& Ebel, 2009). Un ejemplo de ello es el catálogo de Martínez Solares y Mezcua (2002), cuyos datos emplea el Instituto Geográfico Nacional para elaborar la parte histórica del catálogo sísmico oficial español (González, 2017).

Conseguir una mayor completitud de la base de datos sísmicos para una determinada zona geográfica requiere un análisis fidedigno tanto de la sismicidad como de los daños (p. ej. Musson, 1996; Gasperini et al., 1999; Martínez Solares \& Mezcua, 2002; Guidoboni \& Ebel, 2009; García-Mayordomo et al., 2012; Udías, 2015; González, 2017). Por tanto, es necesaria una continua revisión y actualización de la información sísmica, donde las referencias primarias tienen un papel fundamental debido a que presentan la información sin modificaciones posteriores (Martínez Solares \& Mezcua, 2002). En la actualidad, las fuentes históricas originales de información resultan más accesibles gracias a la documentación escaneada y volcada en repositorios digitales, accesibles a través de Internet mediante motores de búsqueda. De este modo, es posible consultar fuentes primarias que en el pasado no pudieron ser empleadas con facilidad, y llegar incluso a identificar nuevos terremotos que no habían sido considerados en los catálogos sísmicos previos, pero que sí habían sido mencionados (Ces Fernández, 2015).

Muchos países, incluída España, disponen de acceso libre a la gran mayoría de las referencias históricas utilizadas en los catálogos nacionales para una mayor credibilidad y transparencia (Martínez Solares \& Mezcua, 2002; Guidoboni \& Ebel, 2009). El catálogo de sismicidad histórica utilizado en este trabajo llega a incluir datos desde el siglo III antes de Cristo, aunque en términos generales están escasamente documentados. A medida que se remonta al pasado, la precisión temporal y espacial así como la intensidad atribuible resultan más complicadas de determinar (González, 2017; Udías, 2017).

La región objeto de estudio en este trabajo es el noroeste de la Península Ibérica, tradicionalmente considerada como una zona sísmicamente estable, ya que se encuentra en una región intraplaca alejada de los bordes de placa activos del sur peninsular (p. ej. Stich et al., 2003; Vicente et al., 2008; Martín-González \& Heredia, 2011; Martín-González et al., 2012). Además, geológicamente la región se encuentra sobre un basamento antiguo (Macizo Ibérico, formado principalmente por rocas prevariscas) y cuencas cenozoicas detríticas de difícil datación, lo que complica el estudio de la actividad reciente de las fallas y la asignación de actividad a las mismas (Martín-Serrano et al., 1996; MartínGonzález \& Heredia, 2011; Martín-González et al., 2014). Sin embargo, varias crisis sísmicas como las de Sarria-Triacastela-Becerreá (Lugo) en los años 1995 y 1997 con terremotos de magnitud hasta 5.3 (López-Fernández et al., 2004; Martín-González, 2005; Martínez-Díaz et al., 2006; Martín-González et al., 2012) manifiestan que esta región intraplaca está presentando un potencial sismogénico significativo de magnitud moderada que previamente no había sido considerado (Martínez-Díaz et al., 2006; Martín-González et al., 2012). La escasez de registros de terremotos en esta zona previos a estas crisis (Martín-González, 2005; Martínez-Díaz et al., 2006) plantea el problema de si esta sismicidad es debida a un episodio anómalo o si ha existido en el pasado pero no ha sido registrada. La escasa información 
sobre terremotos históricos en el catálogo del IGN en la zona noroeste de la Península Ibérica, y el potencial sismogénico evidenciado por el registro instrumental de los últimos años, han sido la motivación de este trabajo.

Por todo ello, el objetivo de esta investigación es revisar, para el noroeste peninsular (Galicia, Asturias, Cantábria, Castilla y León y norte de Portugal), la parte histórica previa a 1755 del catálogo sísmico oficial español, recopilado por el Instituto Geográfico Nacional (Martínez Solares y Mezcua, 2002; IGN, 2018). A partir de la revisión de las fuentes originales presentes en dicho catálogo, modificar parámetros de aquellos terremotos catalogados que sean incoherentes y completar con nueva información disponible. Además, identificar nuevos terremotos gracias a las búsquedas en repositorios en línea de nuevas fuentes bibliográficas. Por último, calcular un rango de intensidad según las escalas EMS-98 y ESI-07, en base a los efectos descritos en los documentos originales. El nuevo catálogo obtenido permitirá también comparar mejor la sismicidad histórica de la región con respecto a la sismicidad después de 1755.

\section{Metodología}

Revisar catálogos sísmicos previos consiste, entre otras tareas, en buscar las fuentes bibliográficas primarias y comprobar el contenido de las mismas, para elaborar un catálogo sísmico mejorado que minimice errores de transcripción. El punto de partida de este trabajo ha sido el catálogo sísmico oficial español publicado por el Instituto Geográfico Nacional (IGN, 2018). Dicho catálogo se basa en esta zona y para este periodo principalmente en el Catálogo sísmico de la Península Ibérica (880 a.C.-1900) elaborado por Martínez Solares y Mezcua (2002). Este catálogo ha sufrido modificaciones en la última versión disponible en la web (González, 2017; IGN, 2018). Sin embargo, ninguna afecta al noroeste peninsular en el periodo temporal analizado. Tras la selección de los terremotos previos a 1755 descritos en la zona a estudio, se han buscado las referencias tomadas en el catálogo del IGN para cada uno de ellos, revisando los textos y buscando a su vez las fuentes originales: Moreira de Mendonça (1758), Perrey (1847), Milne (1912), Sánchez-Navarro (1921), Rey Pastor (1927), Galbis (1932 y 1940) y Mezcua \& Martínez Solares
(1983). A su vez, estos autores se basan en otros documentos, que también han sido revisados y que detallaremos en cada terremoto. Siempre que ha sido posible, se ha buscado la fuente primaria de cada una de las referencias. Se han revisado los terremotos localizados en el noroeste peninsular (Galicia, Asturias, Cantabria, Castilla y León y norte de Portugal) o con epicentros no localizados claramente en estas zonas pero que podrían haberse producido en esta región. Temporalmente se ha estudiado el periodo anterior a 1755, ya que en ese año ocurrió el llamado terremoto de Lisboa que afectó a gran parte de la Península Ibérica (Martínez Solares, 2001) y a partir de entonces supuso un punto de inflexión en el estudio y registro sistemático de los terremotos, mejorando la completitud del catálogo. Ésto permitió tener catálogos más precisos y con mayor número de eventos sísmicos a partir de entonces (Martínez Solares \& Mezcua, 2002). Evidencia de ello es que el número de eventos catalogados entre 1492 (final de la Reconquista) y 1800 es alrededor de 600, cifra que contrasta con los alrededor de 1600 eventos catalogados durante el siglo XIX (Silva-Barroso et al., 2014).

La segunda parte del trabajo se centró en la búsqueda de nueva información sobre terremotos que ya habían sido descritos en el catálogo del IGN (IGN, 2018). En este punto cabe destacar el análisis del catálogo sísmico de Ces Fernández (2015) para Galicia, ya que presenta información recopilada recientemente y con modificaciones respecto del catálogo del IGN para los terremotos localizados en esta región. Además se han encontrado nuevos documentos que no habían sido considerados previamente. Ejemplo de ello son los trabajos de Senos \& Carrilho (2003) y Ferrão et al. (2016). Además, se consultaron posteriores modificaciones de los catálogos como Mezcua et al. (2013) y Udías (2017). Se han modificado algunos parámetros de los terremotos incluidos en esos catálogos a la luz de los documentos originales (ej. fecha, localización, zonas geográficas afectadas, etc.).

Una vez se hubo revisado y modificado el catálogo sísmico con terremotos ya catalogados, se procedió a la búsqueda de otros terremotos no presentes en el catálogo del IGN. Para ello fue muy importante la labor realizada por Ces Fernández (2015), que documentó diez terremotos en el noroeste peninsular 
no incluidos en el catálogo oficial del IGN. Por nuestra parte, se han encontrado otros cuatro eventos que no estaban catalogados ni por el IGN ni por Ces Fernández (2015) (Tabla 1 y 2).

Tras la recopilación de los terremotos en el nuevo catálogo elaborado, se calculó el rango de intensidad en función de los efectos descritos en los textos originales. Fue posible en un total de 18 eventos (Tablas 1 y 2). Los valores de intensidad dados a los terremotos se basan en dos escalas macrosísmicas: la escala europea de intensidad macrosísmica, EMS-98 (Grünthal, 1998), y la escala macrosísmica de efectos ambientales de los terremotos ESI-07 (Michetti et al., 2007). La escala EMS-98 fue elaborada la Comisión Sismológica Europea y evalúa los daños en edificios, el efecto en las personas y los efectos en los objetos y, en menor medida, en la naturaleza causados por los terremotos. La escala ESI-07 ha sido desarrollada por International Union for Quaternary Research y recoge los efectos ambientales en superficie y geológicos producidos por los terremotos (Michetti et al., 2007; Silva-Barroso et al., 2014; Serva et al., 2016; Sánchez \& Maldonado, 2016). Dado que ambas estudian diferentes efectos que producen los terremotos, EMS-98 y ESI-07 se calculan de manera independiente. A pesar de que la escala EMS-98 presenta un apartado de evaluación en entornos naturales, estos efectos fueron estudiados y cuantificados con más detalle en la ESI-07. Finalmente se realizó una representación espacial de los terremotos históricos catalogados (Fig. 1) y se comparó con la distribución de la sismicidad desde 1755 hasta la actualidad (Fig. 2).

\section{Resultados}

Se detallan los terremotos estudiados y analizados en este nuevo catálogo, poniendo entre paréntesis el nombre del terremoto según el catálogo del IGN. Todos estos datos se presentan resumidos en las Tablas 1, 2 y 3 y sus localizaciones se representan en el mapa de la Figura 1.

\section{Italia y Europa 217 a.C. (España 196 a.C.)}

Presente en el catálogo del IGN y Ces Fernández (2015) donde se extraen dos referencias: Galbis (1932) y Moreira de Mendonça (1758). Este último toma la referencia de Patricio (1739), transcrito en el catálogo de Ces Fernández (2015). Además, este terremoto ha sido incluido en el catálogo italiano Gruppo di lavoro CPTI (2004), ubicándolo en la antigua región italiana de Etruria en el mes de junio.

En la revisión, Álvaro González nos ha proporcionado referencias más antiguas, siendo Livius (siglo I a.C.) la más pretérita que habla de dicho terremoto. La traducción al español fue hecha por Villar Vidal (1993):

“... la atención se centró en la lucha en tal extremo, que ninguno de los combatientes notó aquel seísmo que arruinó buena parte de muchas ciudades de Italia y desvió de su curso impetuosas corrientes, empujó el mar hacia los ríos y derruyó montañas con enormes desprendimientos."

Grado de credibilidad: se cataloga de erróneo por los motivos que se explican en el párrafo de localización que ubican al terremoto fuera de la zona de estudio, y considerando que no se debería tener en cuenta en futuros catálogos históricos en España.

Fecha: Se ha modificado la fecha en el catálogo del IGN de 196 a.C. a 217 a.C., ya que ocurrió durante la batalla del Lago Trasimeno que se data actualmente el 21 de junio del 217 a.C. (Goldsworthy, 2000). Este razonamiento fue hecho por Ces Fernández (2015), sin embargo, se desconoce por qué no fue modificada en aquel catálogo.

Localización: Ces Fernández (2015) y el IGN lo sitúan en España, sin embargo no se citan consecuencias del terremoto en España. Finalmente se ha ubicado en Italia y Europa (Patricio, 1739; Villar Vidal, 1993; Gruppo di lavoro CPTI, 2004).

Zonas geográficas afectadas: Se añade Europa ya que los efectos fueron sentidos "em toda Europa" (Patricio, 1739) y España porque según Galbis (1932) y Moreira de Mendonça (1758) los efectos fueron sentidos, sin dar más detalles, en nuestro país.

Intensidad: No ha sido evaluada, ya que se desconoce los efectos del sismo en España.

Norte de Portugal y Galicia 63 a.C. (Norte de Portugal 60 a.C.)

Presente en los catálogos del IGN y de Ces Fernández (2015). Moreira de Mendonça (1758) conduce hasta Faria y Sousa (1678). La referencia más 


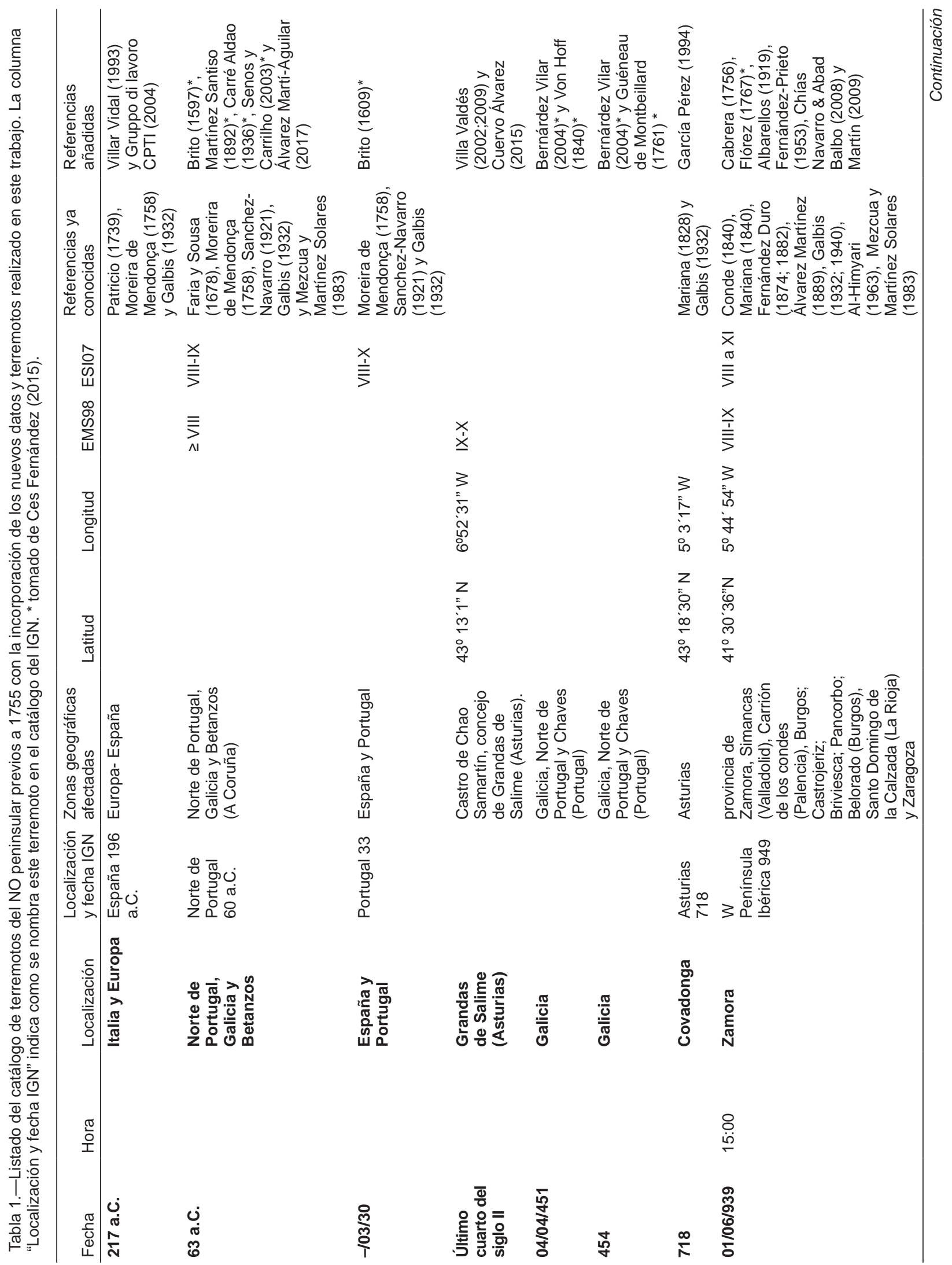




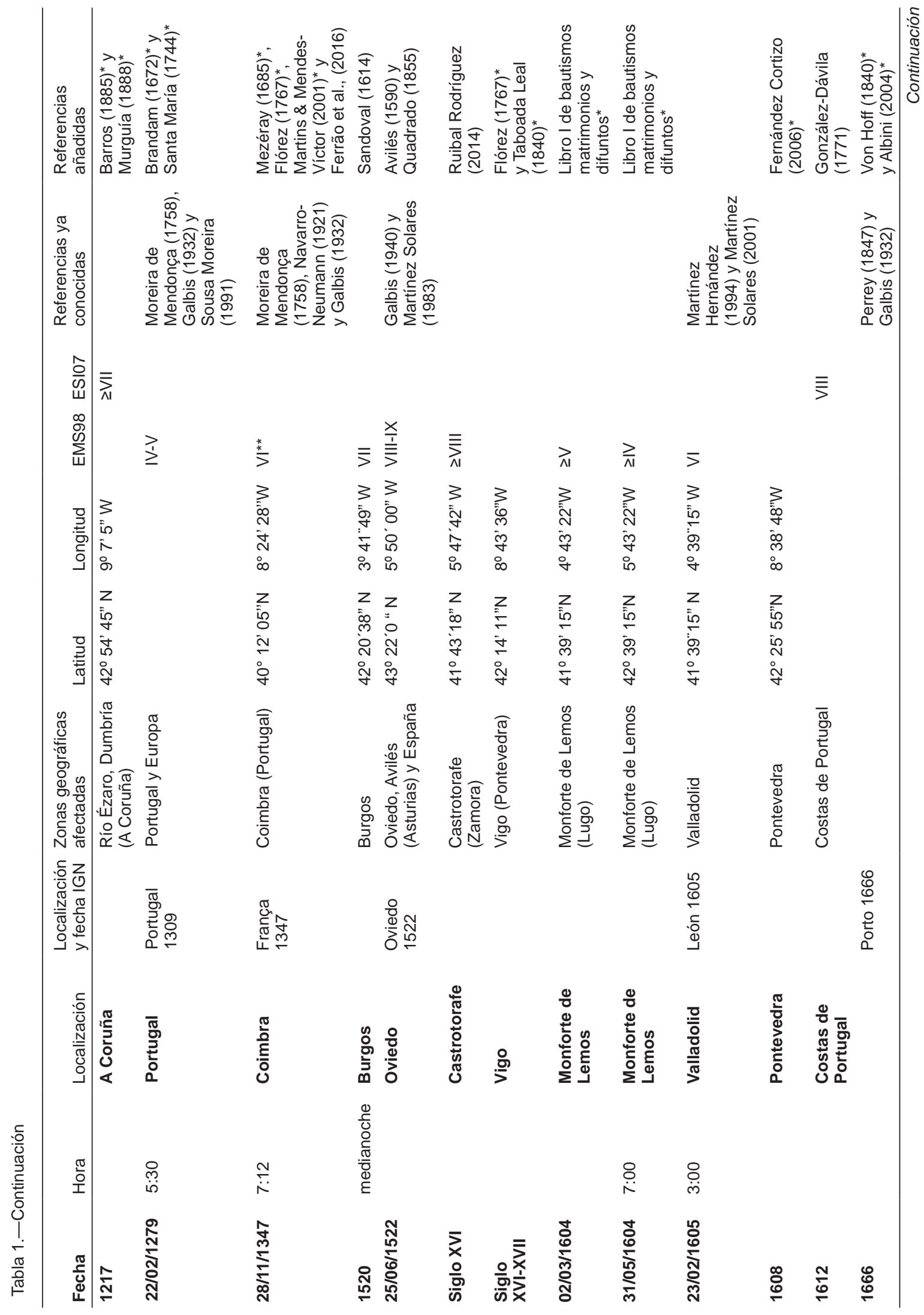




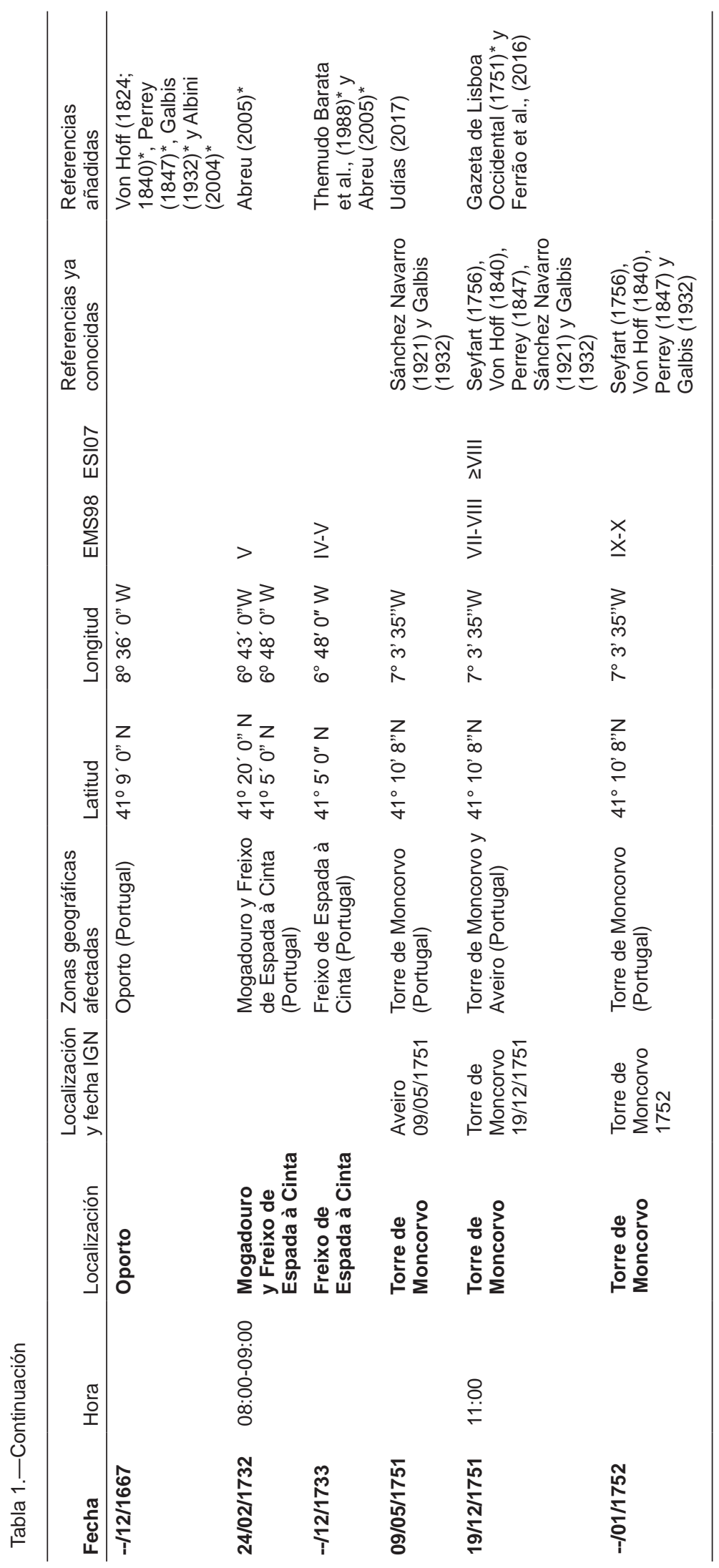


Tabla 2.-Cambios realizados para cada terremoto y parámetro. En la columna "Terremoto" entre paréntesis se indica la localización y fecha según IGN y sin paréntesis la localización y fecha en este catálogo. En la columna "Catálogo", [1]: IGN y [2]: Ces Fernández (2015). N: nuevo, M: modificado, R: revisado. * tomado de Ces Fernández (2015). ** tomado de Ferrão et al., (2016).

\begin{tabular}{|c|c|c|c|c|c|c|c|c|}
\hline Terremotos & Catálogo & Fecha & Hora & Localización & $\begin{array}{l}\text { Zonas } \\
\text { geográficas }\end{array}$ & Referencias & $\begin{array}{l}\text { Grado de } \\
\text { credibilidad }\end{array}$ & Intensidad \\
\hline $\begin{array}{l}\text { Italia y Europa } 217 \text { a.C. } \\
\text { (España } 196 \text { a.C.) }\end{array}$ & {$[1][2]$} & M & & M & $\mathrm{M}$ & $\mathrm{N}$ & Erróneo & \\
\hline $\begin{array}{l}\text { Norte de Portugal y Galicia } 63 \\
\text { a.C. (Norte de Portugal } 60 \text { a.C.) }\end{array}$ & {$[1][2]$} & M & & M & $M^{*}$ & $\mathrm{~N}$ & & $\mathrm{~N}$ \\
\hline Portugal 30 (Portugal 33) & {$[1][2]$} & M & & $\mathrm{R}$ & M & $\mathrm{N}^{*}$ & & $\mathrm{~N}$ \\
\hline Grandas de Salime Siglo II & NUEVO & $\mathrm{N}$ & & $\mathrm{N}$ & $\mathrm{N}$ & $\mathrm{N}$ & & $\mathrm{N}$ \\
\hline Galicia 451 & {$[2]$} & $N^{*}$ & & $N^{*}$ & $N^{*}$ & $N^{*}$ & & \\
\hline Galicia 454 & [2] & $\mathrm{N}^{*}$ & & $\mathrm{~N}^{*}$ & $N^{*}$ & $\mathrm{~N}^{*}$ & & \\
\hline Covadonga 718 (Asturias 718) & {$[1][2]$} & $\mathrm{R}$ & & M & M & $\mathrm{N}$ & En discusión & \\
\hline $\begin{array}{l}\text { Zamora } 939 \text { (W Península } \\
\text { lbérica 949) }\end{array}$ & {$[1][2]$} & M & $\mathrm{N}$ & M & $\mathrm{N}$ & $\mathrm{N}$ & En discusión & $\mathrm{N}$ \\
\hline A Coruña 1217 & [2] & $N^{*}$ & & $\mathrm{~N}^{*}$ & $N^{*}$ & $N^{*}$ & & $\mathrm{~N}$ \\
\hline Portugal 1279 (Portugal 1309) & {$[1][2]$} & $M^{*}$ & $\mathrm{~N}^{*}$ & $\mathrm{R}$ & M & $\mathrm{N}^{*}$ & & $\mathrm{~N}$ \\
\hline Coimbra 1347 (França 1347) & {$[1][2]$} & $\mathrm{R}$ & $\mathrm{N}^{*}$ & $M^{*}$ & $M^{*}$ & $\mathrm{~N}$ & & $\mathrm{~N}^{* *}$ \\
\hline Burgos 1520 & NUEVO & $\mathrm{N}$ & $\mathrm{N}$ & $\mathrm{N}$ & $\mathrm{N}$ & $\mathrm{N}$ & & $\mathrm{N}$ \\
\hline Oviedo 1522 (Oviedo 1522) & [1] & M & & $\mathrm{R}$ & $\mathrm{R}$ & $\mathrm{N}$ & & $\mathrm{N}$ \\
\hline Castrotorafe Siglo XVI & NUEVO & $\mathrm{N}$ & & $\mathrm{N}$ & $\mathrm{N}$ & $\mathrm{N}$ & En discusión & $\mathrm{N}$ \\
\hline Vigo Siglos XVI-XVII & [2] & $N^{*}$ & & $\mathrm{~N}^{*}$ & $N^{*}$ & $N^{*}$ & En discusión & \\
\hline Monforte de Lemos 02/03/1604 & {$[2]$} & $N^{*}$ & & $\mathrm{~N}^{*}$ & $N^{*}$ & $\mathrm{~N}^{*}$ & & $\mathrm{~N}$ \\
\hline Monforte de Lemos 31/05/1604 & {$[2]$} & $N^{*}$ & $\mathrm{~N}^{*}$ & $\mathrm{~N}^{*}$ & $N^{*}$ & $N^{*}$ & & $\mathrm{~N}$ \\
\hline Valladolid 1605 (León 1605) & {$[1][2]$} & $\mathrm{R}$ & $\mathrm{R}$ & M & M & $\mathrm{R}$ & & M \\
\hline Pontevedra 1608 & [2] & $N^{*}$ & & $\mathrm{~N}^{*}$ & $N^{*}$ & $\mathrm{~N}^{*}$ & & \\
\hline Costas de Portugal 1612 & NUEVO & $\mathrm{N}$ & & $\mathrm{N}$ & $\mathrm{N}$ & $\mathrm{N}$ & En discusión & $\mathrm{N}$ \\
\hline (Porto, 1666) & {$[1][2]$} & $\mathrm{R}$ & & $M^{*}$ & $M^{*}$ & $N^{*}$ & Erróneo & \\
\hline Oporto 1667 & {$[2]$} & $N^{*}$ & & $\mathrm{~N}^{*}$ & $N^{*}$ & $N^{*}$ & & \\
\hline $\begin{array}{l}\text { Mogadouro y Freixo de Espada } \\
\text { à Cinta } 1732\end{array}$ & [2] & $N^{*}$ & $N^{*}$ & $N^{*}$ & $N^{*}$ & $N^{*}$ & & $\mathrm{~N}$ \\
\hline Freixo de Espada à Cinta 1733 & [2] & $\mathrm{N}^{*}$ & & $\mathrm{~N}^{*}$ & $N^{*}$ & $N^{*}$ & En discusión & $\mathrm{N}$ \\
\hline $\begin{array}{l}\text { Torre de Moncorvo 09/05/1751 } \\
\text { (Aveiro 09/05/1751) }\end{array}$ & {$[1]$} & $\mathrm{R}$ & & M & M & $\mathrm{N}$ & & \\
\hline $\begin{array}{l}\text { Torre de Moncorvo 19/12/1751 } \\
\text { (Torre de Moncorvo 19/12/1751) }\end{array}$ & {$[1][2]$} & $\mathrm{R}$ & $\mathrm{R}$ & $\mathrm{R}$ & $\mathrm{M}$ & $\mathrm{N}^{*}$ & & $M$ \\
\hline $\begin{array}{l}\text { Torre de Moncorvo enero } 1752 \\
\text { (Torre de Moncorvo 1752) }\end{array}$ & {$[1][2]$} & $\mathrm{R}$ & & $\mathrm{R}$ & $\mathrm{R}$ & $\mathrm{R}$ & & $\mathrm{N}$ \\
\hline
\end{tabular}

antigua, tomada de Ces Fernández (2015), es de Brito (1597). El autor Martínez-Santiso (1892) describió cómo fue el terremoto en Betanzos. Las referencias más modernas fueron Carré-Aldao (1936), tomado de Ces Fernández (2015), y Senos y Carrilho (2003) y como referencia nueva Álvarez Martí-Aguilar (2017).

Fecha: Según Álvarez Martí-Aguilar (2017), la referencia más antigua, Brito (1597), habla del año 63 a.C “Anno 3899. 63 (...) Quasi por estes annos, ou muito poucos antes". Por ello, el año ha sido modificado al 63 a.C.

Localización: Al Norte de Portugal (IGN), se le añade Galicia (Brito, 1597) y, en particular, Betanzos (Martínez-Santiso, 1892).

Zonas geográficas afectadas: Se consideran las citadas por Ces Fernández (2015): Norte de Portugal, Galicia y Betanzos. El catálogo del IGN sólo cita el norte de Portugal como zona afectada. 


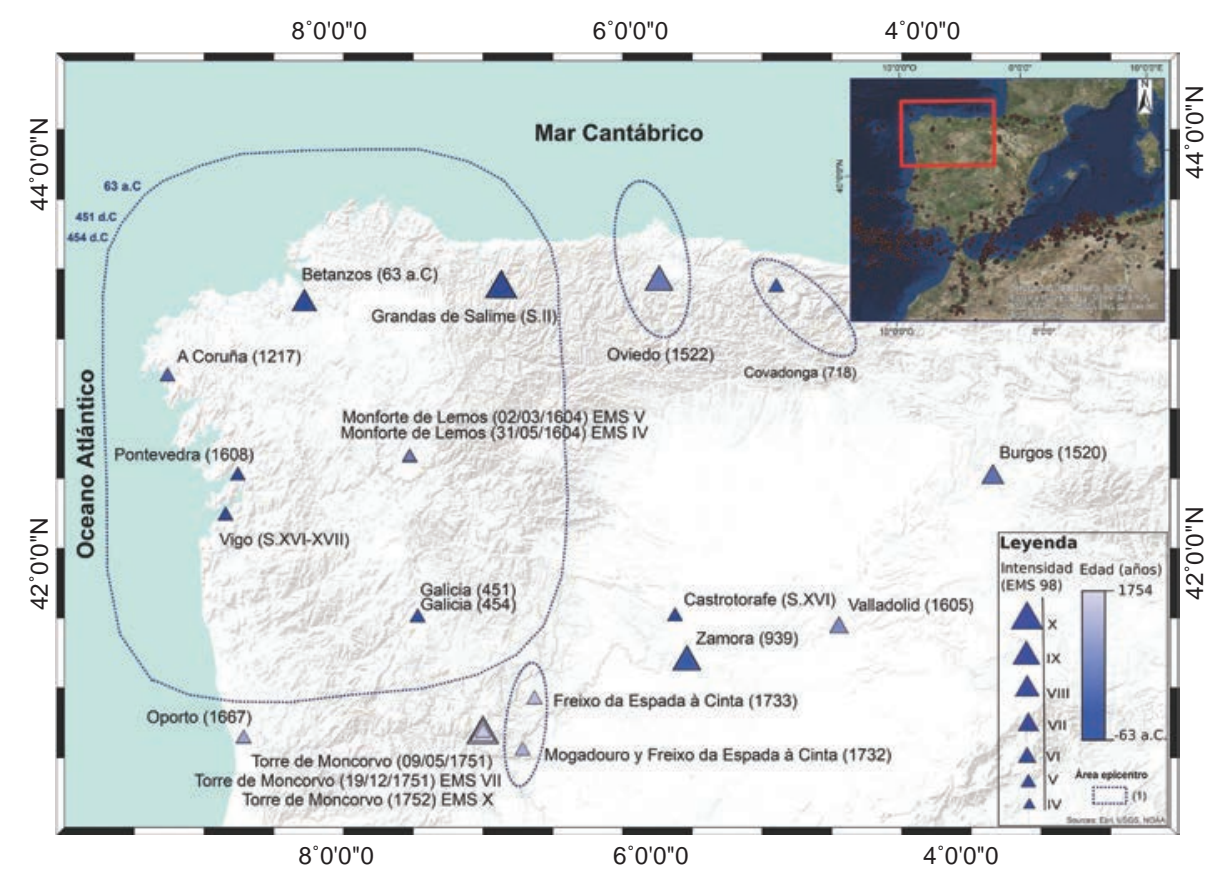

Figure 1.-Mapa con la localización de los terremotos estudiados que forman parte del nuevo catálogo de este trabajo (triángulos) o región de la posible localización epicentral (área de puntos).

Intensidad EMS-98: Efectos en las personas: " $\mathrm{La}$ gente se retiró a habitar en los campos, y las montañas” (Moreira de Mendonça, 1758). “...ivan huyendo las personas a las montañas, tratando cada uno tanto de si solo, que ni los maridos se acordaban de las mujeres, ni ellas de los hijos; ni alguno de otra cualquier obligacion o interés" (Brito, 1597; Faria y Sousa, 1678). "notable temblor de la tierra, en la costa de Portugal y Galicia” (Brito, 1597). “...se arruinarán muchos lugares, y preceo [sic.] cuán tanta cantidad de gente...” (Brito, 1597)”...experimentó Betanzos los efectos de un gran terremoto" (Martínez-Santiso, 1892). Daños en edificios: “arruinó muchos edificios, y lugares enteros” (Moreira de Mendonça, 1758). Este terremoto fue descrito como "notable temblor de la tierra" y se identifica como las poblaciones huyeron. Que algunas personas se asusten indica una intensidad mínima de V. En segundo lugar, “arruinó muchos edificios, y lugares enteros” Brito (1597). Se entiende que algunos edificios sufrieron daños muy severos o se destruyeron. Para que suceda esto la intensidad mínima EMS-98 debe ser VIII, la cual provoca los primeros colapsos en los edificios más vulnerables.
Intensidad ESI-07: Oleaje y tsunamis: "Y el mar saliendo en algunas partes de sus ordinarios límites, ocupó mucha parte de la tierra, dejándola en otros lugares descubierta" (Brito, 1597; Faria y Sousa, 1678; Moreira de Mendonça, 1758). Otros efectos: “...un terremoto, que causó grandes desgracias ...llegó a producir alteración en la configuración de Betanzos” (Martínez-Santiso, 1892). Esta descripción parece encajar con un tsunami. Los primeros tsunamis causados por eventos sísmicos aparecen en intensidad ESI-07 de VIII. Sin embargo, estos serían pequeños. Según el autor, "ocupó mucha parte de la tierra". La intensidad IX tiene más semejanza con este suceso donde los tsunamis alcanzar un run-up de varios metros, provocando la inundación de zonas extensas. En conclusión, se otorga una intensidad máxima ESI-07 de IX. Por otro lado, por ubicarse Betanzos en una ría, los efectos por tsunami se amplificarían, luego podría haberse producido un oleaje anómalo de escala métrica que inundase gran parte de la tierra. Una intensidad ESI-07 de VIII sería el valor mínimo para producir dichos efectos. 


\section{Portugal 30 (Portugal 33)}

Ambos catálogos, Ces Fernández (2015) e IGN, hacen referencia a Galbis (1932) cuya fuente original es Sánchez-Navarro (1921). A partir de los trabajos de Ces Fernández (2015) y el IGN, se llega a la referencia Moreira de Mendonça (1758) cuya fuente proviene de Brito (1609).

Fecha: Se cambia del año 33 d.C (IGN) al año 30 d.C. Se sitúa el suceso en "marzo [...] a los años dieciséis de su monarquía [...] imperio [...] Tiberio César" (Brito, 1609). Según el historiador romano Suetonio (121 d.C.) el año dieciséis de su reinado se corresponde con el 30 a.C. (fue emperador desde septiembre del año 14 d.C. hasta el 37 d.C.) (Rolfe, 1913). Por tanto, se modifica la fecha respecto el catálogo IGN que lo sitúa en el 33 d.C. En el catálogo de Ces Fernández (2015) se realiza este mismo razonamiento.

Zonas geográficas: Han sido modificadas respecto a los dos catálogos, al hablar de España y Portugal como lugares donde se produjeron los efectos (Brito, 1609).

Intensidad ESI-07: Agrietamientos y fracturación del terreno: "Se mostraban rocas abiertas de este terremoto" (Brito, 1609). Se trataría de fracturación en sustrato rocoso lo cual ocurre a intensidad mínima de VIII y llegando a un máximo de X.

\section{Grandas de Salime (Asturias) último cuarto del siglo II}

Es un evento nuevo. No está recogido en los catálogos del IGN ni en Ces Fernández (2015).

Las referencias provienen de Ángel Villa Valdés, arqueólogo en el Museo arqueológico de Asturias, durante las investigaciones arqueológicas sobre el castro asturiano de Chao Samartín.

En primer lugar, Villa Valdés (2009), justifica que un terremoto fuera la causa principal del abandono de dicho castro:

"Es probable que la mengua de la producción aurífera restara paulatina importancia al vetusto enclave pero no explica todo ello de manera satisfactoria el sorprendente hallazgo sobre los suelos públicos de joyas y monedas, o el brutal desplome, de una vez, de grandes muros, o la abundancia de los ajuares domésticos bajo las ruinas. Incongruentes tales hechos con el abandono paulatino del caserío, germina la idea justificada de la ruptura violenta del equilibrio, del terremoto devastador, argumento en absoluto extravagante en una comarca con una acreditada actividad sísmica."

[...]Durante el último cuarto del siglo II d.C. un terremoto devastó el centenario poblado. No era la primera vez que el lugar sufría un desastre de esta naturaleza -así lo prueban las estratigrafías asociadas a las defensas de la Edad del Hierro- sin embargo, en esta ocasión, la ruina sobrevino en un tiempo de imparable declive en la ocupación de los castros, precipitando de esta forma el ocaso definitivo del Chao Samartín como asentamiento estable."

Villa Valdés (2002) y Cuervo Álvarez (2015) detallan la arquitectura del poblado antes del suceso, "espacios compartimentados interiormente mediante tabiques de piedra o agrupadas... pavimentos de hormigón y cargas murales" (Villa Valdés, 2002), "Los muros fueron fabricados con mampuestos de talla informe alineados sobre su cara externa y amasados con mortero de cal...está constituido por dos plantas con escalera de piedra...columnas de un granito" (Cuervo Álvarez, 2015).

Intensidad EMS-98: Se habla de efectos en objetos: "hallazgo sobre los suelos públicos de joyas y monedas además de abundancia de ajuares domésticos bajo las ruinas" (Villa Valdés, 2009). Se trataría de caída de objetos pequeños, siendo una intensidad mínima de V la causante de tal efecto. Por otro lado, existen efectos en las edificaciones, "el brutal desplome, de una vez, de grandes muros...un terremoto devastó el centenario poblado” (Villa Valdés, 2009). La arquitectura estaba basada en paredes de piedra. La intensidad que provoca la destrucción de muchos edificios de clase de vulnerabilidad A es IX. Cabe mencionar, que en intensidad VIII se provoca la destrucción de algunos edificios de vulnerabilidad A, pero los detalles de la destrucción del poblado "un terremoto devastó el centenario poblado" parecen indicar estragos mayores. Por todo ello, se le daría un rango mínimo de intensidad IX. Siguiendo la EMS-98 y la descripción de la tipología constructiva empleada en el castro de Chao Samartín "opus incertum” (Cuervo Álvarez, 2015), nos lleva a pensar en la presencia de edicios de roca simple con buena calidad de ensamblaje y, según la EMS-98, atribuible a vulnerabilidad B. Dado que se produce la destrucción 
de edificios de vulnerabilidad $B$, resulta coherente atribuir un rango máximo de intensidad de $\mathrm{X}$.

\section{Galicia 451}

Nuevo para el IGN pero catalogado por Ces Fernández (2015). La referencia inicial de Ces Fernández (2015) se encuentra en la obra de Bernárdez Villar (2004) que recoge la descripción del obispo Idacio que vivió durante los siglos IV-V en la ciudad romana de Aquae Flaviae, actual Chaves (norte de Portugal) en la región de Gallaecia. El historiador Bernárdez Vilar (2004) tradujo del latín los manuscritos al gallego. En el catálogo de Ces Fernández (2015) se encuentra otra referencia (Von Hoff, 1840) que data este terremoto en el año 448.

Fecha: Se transcribe la fecha de Ces Fernández (2015).

Zonas geográficas afectadas: Se ha considerado la misma ubicación proporcionada por Ces Fernández (2015). Gallaecia fue una provincia romana que abarcaba el norte de Portugal, la actual Galicia y otros territorios cercanos cuyos límites se situaban hasta la provincia de Zamora (Fontana-Tarrats, 1977). Además, Chaves era la localidad donde vivía el clérigo que dejó constancia de los hechos (Ces Fernández, 2015).

Intensidad: No hay suficiente información para evaluar la intensidad.

\section{Galicia 454}

Este terremoto, nuevo con respecto al catálogo del IGN, ha sido referenciado de Ces Fernández (2015). La referencia de Ces Fernández (2015), fue tomada de la obra de Bernárdez Vilar (2004), al igual que el terremoto de Galicia 451, citándose otro temblor en el año 454 en Galicia. Además, en el catálogo de Ces Fernández (2015) se encuentra la obra de Guéneau de Montbeillard (1761) quien relata un terremoto y una posible aurora boreal en el 454.

Fecha: En ambas referencias aparece un número 454 que se considera que es el año del suceso "[año 454]” (Bernárdez Vilar, 2004).

Zonas geográficas afectadas: Se utilizan los mismos lugares y las mismas razones que en el sismo catalogado de Galicia del 451.

Intensidad: No es posible obtener una intensidad, ya que no se detallan efectos del suceso.

\section{Covadonga 718 (Asturias 718)}

Se trata de un terremoto del catálogo del IGN y descrito en Ces Fernández (2015), que fue incorporado en los catálogos sísmicos por Galbis (1932). A su vez Galbis empleó como fuente a Mariana (1828) quien relata la caída del monte Auseva al río Deva.

Una referencia nueva con respecto al catálogo del IGN y Ces Fernández (2015), es el artículo de García Pérez (1994). En él se refiere a un texto del siglo XI que describe el terremoto ocurrido en Asturias rescatado de una obra griega del siglo II, del que parece copiado, pero situando éste los mismos hechos en Grecia. La versión asturiana proviene de la Crónica de Alfonso III, versión rotense (siglo X), transcrita en García Pérez (1994):

"Una vez salieron de la cueva [los cristianos] a combatir, los musulmanes se dieron a la fuga... Y en el mismo lugar fueron muertos 124.000 de los musulmanes, y 63.000 que habían quedado subieron a la cima del monte Auseva, y por el lugar de Amuesa bajaron a la Liébana. Pero ni siquiera esos escaparon... Cuando marchaban por lo alto del monte que está sobre el río Deva... ocurrió que... en Cosgaya ese monte, revolviéndose desde sus fundamentos [terremoto], lanzó al río a los 63.000 hombres y allí los sepultó a todos el tal monte.... a estos árabes que perseguían a la Iglesia del Señor.”

La versión griega del escritor Pausanias (II), se encuentra también en García Pérez (1994) y dice lo siguiente:

"El dios dio señales contra los bárbaros enseguida con gran evidencia... Hubo una gran helada y nevada, y se deslizaron desde el Parnaso unas grandes rocas, se rompieron unos precipicios, y vinieron a dar sobre los bárbaros que caían., treinta y aún más cada vez... Por la noche, en la retirada..., por la locura que da el dios, los gálatas se dieron muerte unos a otros,... sin notar que todos hablaban la misma lengua... Toda la tierra que ocupaba el ejército galata, tembló fuertemente [terremoto]... Ninguno regresó a su país... Ha de saberse que esto sucedió así...”

Grado de credibilidad: La situación política y religiosa, según García Pérez (1994), explicaría la falta de textos que acreditaran la veracidad de los hechos expuestos en crónica de Alfonso III (siglo X) hasta la segunda mitad del siglo XIX. 
El terremoto se sitúa dentro del período histórico de la Reconquista, donde los reinos cristianos de la Península Ibérica fueron consiguiendo militarmente territorios que estaban bajo dominio musulmán. Según la historiografía cristiana, la batalla de Covadonga marcaría el inicio de la Reconquista. Además, García Pérez (1994) ofrece justificaciones que defienden la copia de este terremoto al encontrar similitudes entre las versiones asturiana y griega. Por todo ello, y sumado al posible origen no sísmico del deslizamiento, este terremoto se cataloga como en discusión.

Fecha: Se han transcrito del catálogo del IGN y Ces Fernández (2015). En el texto de Galbis (1932), referente para IGN y Ces-Fernández, se escribe “718”. Este mismo autor data el evento en el año 99 de la Hégira (calendario musulmán) correspondiente con el año 717 ó 718 d.C (Moréri, 1753; Ríos Saloma, 2011). Además, la fecha de la batalla de Covadonga no es precisa, datándose en el 718 ó 722 (Monsalvo Antón, 2014).

Localización y zonas geográficas afectadas: Se han modificado ambas, en el IGN y Ces Fernández (2015) el terremoto se localiza en Asturias. Sin embargo, el monte Auseva se encuentra concretamente en Covadonga, por tanto se sitúa el terremoto en esta localidad asturiana. Aunque la vertiente del río Deva estaría cerca de la Hermida, unos $35 \mathrm{~km}$ al este de Covadonga, en este trabajo se mantiene la localización en Covadonga por motivos históricos.

Intensidad: Se ha decidido no evaluar al catalogar el sismo de discutible.

\section{Zamora 939 (W Península Ibérica 949)}

Es un terremoto presente en los catálogos del IGN y de Ces Fernández (2015) con localización en una amplia zona del Oeste de la Península Ibérica. Las fuentes principales fueron Galbis (1932; 1940) y Mezcua \& Martínez Solares (1983). Las referencias más importantes de Galbis (1932) fueron: Fernández Duro (1874; 1882), Conde (1840), Álvarez Martínez (1889) y al-Himyari (1963). Además hemos encontrado nuevas referencias, siendo destacables Cabrera (1756) por ser la referencia más antigua que describe el terremoto, Chías Navarro y Abad Balbo (2008) y Martín (2009), este último tradujo del latín “Annales
Castellani Antiquiores” y “Annales Castellani Recentiores (siglos XII-XIII)” y además nos condujo hasta la referencia más antigua "Chronicon Sampiri (siglos X-XI)” del año 999. Ces-Fernández (2015) encontró los textos transcritos por Flórez (1767) de “Chronicon Burgense (siglos XIII-XIV)” y "Anales Compostelanos (siglos XIII-XIV)".

Grado de credibilidad: En varios trabajos se describió un temblor de tierra (Cabrera, 1756; FernándezDuro, 1882; Álvarez-Martínez, 1889; Galbis, 1932; Fernández-Prieto, 1953; Martínez-Solares y MezcuaRodríguez, 2002), encontrándose la referencia más antigua al suceso en Annales Colonienses Breves (MGH, 2018). Se trata de un terremoto ampliamente detallado por Fernández Duro (1882). Sus referencias principales son Fernández Duro (1874), Conde (1840), De Morales (1791), Anales Compostelanos, además de la descripción realizada por Pedro Cortijo (Inspector del Cuerpo de Caminos). Fernández Duro (1882) establece con precisión los daños en la ciudad de Zamora al detallar la toponimia. Sin embargo, Fernández Duro (1882) parece que cometió un error en la transcripción de su último párrafo, que tomó de Conde (1840), y el cual asoció con el terremoto de Zamora del 939. Dicho párrafo, describe efectos del terremoto del 881 de Cádiz ya que Conde $(1840)$ al comienzo del párrafo escribe: "En el año 267, día jueves, 22 de la luna de Xawâl, tembló la tierra...”. El año 267 de la Hégira corresponde con el 881. Además Conde (1840) indica que estos efectos se sintieron en la España meridional. Por todo ello, los efectos descritos en este párrafo relativos al terremoto de Cádiz, no han sido tenidos en consideración para valorar la intensidad.

No fue Fernández Duro (1882) el único que se refirió al terremoto del 939, sino que anteriormente Cabrera (1756) ya mencionaba este suceso: "reventò en el Mar un Temblor”. El trabajo de Masdeu (1793) fue basado en las referencias más antiguas al que el autor tuvo acceso, siendo una de ellas Anales Breves (Annales Colonienses Breves) a cuya transcripción hemos tenido acceso (MGH, 2018) y que indica: "939. terremotus".

Sin embargo, otros autores relacionan con otros fenómenos lo sucedido en el contexto de la batalla de Simancas en el 939. Así algunos describieron un posible eclipse solar (Conde, 1840; Albarellos, 1919; al-Himyari, 1963; Rodríguez-Fernández, 
1998; Martín, 2009), mientras que otros relataron un posible incendio (Nieremberg, 1643; Cabrera, 1756; Flórez, 1767; Fernández-Duro, 1882).

Dada las diferentes descripciones del fenómeno ocurrido y la extensión del área afectada, este terremoto se cataloga en discusión.

Fecha: El IGN se basó en “Anales Compostelanos” para dar la fecha en el año 949 d.C. Por otro lado, "Chronicon Burgense" fue anterior e indica como fecha 939, hecho considerado por autores como Cabrera (1756). En cuanto al día, en el Chronicon Burgense, transcrito por Flórez (1767), se escribe “Calenda. Sábado de Junio", palabra que designa al día 1 de cada mes. Además, coincide el día de la semana, sábado, con la fecha 1 de junio de 939 (UGR, 2018). Del mismo modo, FernándezPrieto (1953), basado en "Anales Compostelanos" y "Chronicon Burgense" se refiere a "terremoto del día $1^{\circ}$ de junio del 939”. Por ello se tomó esta fecha como válida, coincidiendo con Ces Fernández (2015) en día y mes.

Hora: En Chronicon Burgense se expresa "hora nona”, interpretado tanto por Ces-Fernández (2015) como por Martín (2009) como 03:00h. Por ello se añade este parámetro.

Localización: Atribuido al W de la Península Ibérica por el IGN, se ha modificado y localizado en la provincia de Zamora. Además de ser la provincia donde se produjeron los mayores daños, varios autores nombran la localidad de Zamora como afectada (Cabrera, 1756; Flórez, 1767; Fernández Duro, 1882; Álvarez Martínez, 1889; Albarellos, 1919; Fernández-Prieto, 1953). En Galbis (1940) este terremoto se atribuye a la Cuenca del Duero, donde se ubica la provincia de Zamora. Por todo ello, se modificó la localización a la provincia de Zamora.

Zonas geográficas: Se añadieron Zamora, Carrión de los Condes (Palencia), Burgos, Castrojeriz (Burgos), Briviesca (Burgos), Pancorbo (Burgos), Belorado (Burgos), Santo Domingo de la Calzada (La Rioja), y Zaragoza, según Chronicon Burgense transcrito por Flórez (1767) y Anales Compostelanos transcrito por Mariana (1840). La gran zona afectada $\left(40.000 \mathrm{Km}^{2}\right)$ podría indicar un terremoto de fuente lejana. Sin embargo las descripciones relativas a la provincia de Zamora y los topónimos (p. ej. río Esla, río Valderaduey, puente del Ricobayo, río Duero, San Lázaro, Olivares) evidenciarían que el terremoto del 939 se produjo en la provincia de Zamora.

Intensidad EMS-98: Efectos en las personas: Conde (1840) “ horrorizando los ánimos de la inexperta juventud que no había visto en su vida cosa semejante.", al-Himyari (1963) “llenó de terror a los nuestros y los infieles". Efectos en edificios: Fernández Duro (1882) “el famoso puente construido por los romanos mole entera de la fábrica, arrancada de cuajo de sus cimientos el puente romano se inclinó y cayó entero hacia el origen de la corriente, arrancado desde el cimiento siendo la oscilación la que tumbó el puente" "El fenómeno causaría sin duda considerable daño en los edificios de la ciudad, y singularmente en los sólidos muros de Alfonso el Magno" "debió hundirse también el puente de Ricobayo sobre el Esla se reconocían en el fondo del rio algunos pedazos enteros de los dos arcos destruidos, los que se conservaban sin haberse desprendido ninguna dovela, y la porción de pila que se conservaba en pié estaba ladeada y fuera de cimiento.", Chías Navarro y Abad Balbo (2008) "Poco queda del puente primitivo, apenas los restos de seis pilas y de las cimentaciones de otras. También es apreciable el arranque de un par de bóvedas, que eran de cañón. Se puede observar vestigios del revestimiento de sillería, que estaba formada por sillares de dimensiones muy regulares y bien labrados.”, Fernández Duro (1874) “...puente de sillería que, aunque arruinado en parte, existe hoy sobre el río Esla y llaman de Ricobayo ", Fernández-Prieto (1953) "Para el paso del Duero existió el puente romano algunos historiadores zamoranos atribuyen su demolición o ruina total al terremoto del día $1^{\circ}$ de junio del 939...”. En relación al efecto sobre las personas se desconoce si fueron algunos o muchos quienes se asustaron, luego se describió una intensidad mínima EMS-98 de V. En cuanto a los daños en edificaciones se habla de daños considerables y caída de dos puentes (puente romano sobre el río Duero y puente romano de Ricobayo sobre el Esla). El rango de intensidad mínima para producir la caída de edificios de vulnerabilidad C es de VIII. Si el edificio tuviera una vulnerabilidad D hablaríamos de una intensidad máxima de IX. Por tanto, se establece un rango de intensidad EMS-98 de VIII a IX.

Intensidad ESI-07: oleaje anómalo de masas de agua: Fernández Duro, (1882) “Valderaduey corría 
antiguamente por el sitio en que hoy se halla la Estación del ferro-carril ”, " el Valderaduey se vio obligado á torcer á la izquierda buscando desnivel para arrojarse en el Duero", "El Duero [ ] sintió hundir su lecho por el lado de la ciudad”. Se estaría describiendo un oleaje anómalo por cambio temporal o permanente del cauce de los ríos, la intensidad mínima para cambios métricos es de VII. Además, se hace referencia al hundimiento del lecho del Duero, siendo significativos a partir de ESI-07 VIII, lo cual es necesario para desviar el cauce del Valderaduey. Por último fue sentido en unos $40.000 \mathrm{Km}^{2}$, según el listado de poblaciones afectadas en el Chronicon Burgense, transcrito por Flórez (1767), y Anales Compostelanos, transcrito por Mariana (1840), siendo la intensidad ESI-07 de XI. En definitiva, los efectos descritos llevan a establecer un rango de intensidad ESI-07 mínimo de VIII y máximo de XI considerando el área afectada.

\section{A Coruña 1217}

Se trata de un nuevo terremoto con respecto al catálogo del IGN, pero presente en Ces Fernández (2015). La primera referencia, utilizada por Ces Fernández (2015), proviene de Barros (1885). Una segunda referencia, Murguía (1888), relata con mayor detalle el suceso, como una caída del monte sobre el río Ézaro.

Fecha: Aparece señalada en las dos referencias, “año 1217”.

Localización: Los desprendimientos podrían haberse producido en la zona más al norte del Monte Pindo (Barros, 1885) por donde discurre el río Ézaro y donde a día de hoy se encuentra la cascada de éste. Los bloques de piedra habrían bloqueado la salida natural del río (Barros, 1885), el cual acabó desembocando al mar en la cascada que continua hasta el día de hoy.

Zonas geográficas afectadas: Las secuelas del terremoto son apreciadas a lo largo del "río Ézaro" (Murguía, 1888).

Intensidad ESI-07: Movimientos de ladera: “... grandes rocas cuarteadas y desdeñosamente hacinadas [] pérdida de nivel de la montaña, que al hundirse de un lado[] perdió la elevada montaña el equilibrio, desplomándose sobre el estrecho valle, rodando los escombros hasta las orillas del mar (Barros, 1885).”, “Pudimos estudiar el primitivo albeo del río Ézaro, y el nuevo curso que sigue hoy, obligado por el acontecimiento [] despeñándose verticalmente por uno de los acantilados de la costa (Barros, 1885)." $y$ "[ ] un gran terremoto cambió en aquellos lugares, no sólo la faz del terreno sino también el alveo (sic) del río, el cual se desploma hoy verticalmente por uno de los acantilados de la costa (Murguía, 1888)"

Por otro lado, en esta misma descripción se observa como se produjo un desprendimiento de rocas sobre el río Ézaro que bloqueó su antiguo cauce y lo desvió. Para lograr cambiar el curso fluvial del río, el movimiento de rocas debe ser significativo $\left(10^{3}-10^{5} \mathrm{~m}^{3}\right)$, siendo destacable a partir de intensidad VII. Destacar que se detallan cambios permanentes, "quedaban indelebles señales", sin embargo no supone ninguna información adicional para el cálculo de la intensidad. Por tanto, y suponiendo un origen sísmico en la caída de las rocas, la intensidad estimada para este terremoto sería de VII o superior.

\section{Portugal 1279 (Portugal 1309)}

Este terremoto se encuentra en el catálogo del IGN y en Ces Fernández (2015). La referencia más antigua, citada por Ces Fernández (2015), es Brandam (1672). Del mismo modo, ya había referencias a este terremoto en Galbis (1932), cuya referencia es Moreira de Mendonça (1758). Una tercera referencia tomada del catálogo de Ces Fernández (2015) es Santa María (1744).

Fecha: Hay numerosas interpretaciones sobre la fecha del terremoto, como por ejemplo el catálogo del IGN que data el suceso el 22 de febrero de 1309 o varios autores que lo ubicaron en 309 probablemente debido a un error en la transcripción de la fecha (Moreira de Mendonça, 1758; Terremotos em Portugal, 1923; Galbis, 1932). Ces Fernández (2015) pudo consultar el Libro da Noa de Coimbra, la referencia original, conservada en el Archivo Nacional Torre do Tombo, donde aparece escrito “Era 1317”, correspondiente al año 1279. Este mismo razonamiento también fue realizado por Sousa Moreira (1991), quien data el terremoto en el año 1279. Al ser por tanto la referencia más antigua, en este trabajo se considera más coherente datarlo en el año 1279. El mes y el día están escritos en 
el texto de Moreira de Mendonça (1758), “mes de Febrero [...] 22".

Hora: A las cinco y media de la mañana, según Ces Fernández (2015) quién recoge la información del catálogo del Instituto Geofísico do Infante D. Luis (IGIDL). Este parámetro es nuevo pero transcrito de Ces Fernández (2015).

Zonas geográficas afectadas: Se ha decidido incluir Europa como zona afectada, "temblor de tierra espantoso, no solo en este reino, sino general por todos los demás de Europa" (Brandam, 1672). De acuerdo a la baja intensidad y las grandes zonas afectadas, podría tratarse de un terremoto lejano lo que estaría apoyado en el catálogo de Ferrão et al. (2016) con epicentro en el Océano Atlántico al suroeste de la Península Ibérica.

Intensidad EMS-98: Se trata de un temblor de tierra que fue sentido por la población "un temblor, de tierra espantosa" (Brandam, 1672) pero que no ocasionó desgracia "no ha sido perjudicial a nuestro Portugal, ni aún España” (Brandam, 1672). Por tanto, estaríamos hablando de un terremoto de intensidad IV-V, ya que a estas intensidades los efectos son sentidos por la población pero no causan daño en edificaciones.

\section{Coimbra 1347 (França, 1347)}

En el catálogo del IGN se localiza un terremoto en França (Portugal) en el año 1347. La referencia más antigua viene de Moreira de Mendonça (1758).

"A 28 de Novembro houve hum grande Terremoto em Portugal. Em França, foi tão violento, que postrou Cidades, e abriu huma tão profunda cova, que parecia, que o Inferno quería tragar o genero humano"

Según Ces Fernández (2015) la referencia que toma Moreira de Mendonça (1758) del terremoto de Portugal, viene en el Livro da Noa cuya traducción se incluye en la obra Provas da Historia genealógica da casa real portuguesa, tomo I (1739), posteriormente transcrita por Flórez (1767).

"Era de M. e CCC.LXXXV. XXVIIJ. Dias de Novembro em feria quarta da manhaá tremeo a terra em Coimbra."

Según ésto, el terremoto se localizaría en Coimbra (Portugal). Ferrão et al., (2016) también cataloga el terremoto en Coimbra en 1347.
Flórez (1767) y Mezéray (1685) trataron dos terremotos, uno en Coimbra y otro en Francia, en portugués França. Es probable que la interpretación del texto Moreira de Mendonça (1758) haya llevado a esta confusión, puesto que Francia en portugués es França, como la localidad portuguesa de França. De esta manera, Mezéray (1685) relata un terremoto en Francia en 1347 (Ces Fernández, 2015).

«Durant tous ces temps les hommes estoient tourmentez de tous les fléaux du Ciel. Un tremblement de terre universel, mesme en Espagne \& aux Païs Septentrionaux, renversoit les Villes toutes entieres, déracinoit les arbres \& les montagnes, \& remplisfoit les campagnes d'abysmes si profondes, qu'il sembloit que l'enfer eut voulu engloutir le genre humain. Cette disgrace n'estoit pas si grande \& ne fit point d'effets si funestes que ceux que produisit la peste, qui depeupla la face de la terre de plus de la moitié de ses Habitans »

Hora: 7 h y 12 minutos. Tomado de Ces Fernández (2015) quien lo toma de Martins \& Mendes-Víctor (2001).

Localización: Se modifica a la ciudad de Coimbra, tal y como proponen Ces Fernández (2015) y Ferrão et al., (2016).

Intensidad: tanto el terremoto de Coimbra como el de Francia se localizan fuera de la zona de estudio, luego no se ha calculado la intensidad. Sin embargo, se ha tomado de Ferrão et al., (2016) como intensidad MMI de VI. Dado que la escala utilizada en este trabajo es EMS-98, se ha convertido a intensidad EMS-98 de VI (Musson et al., 2010).

\section{Burgos 1520}

Se trata de un terremoto nuevo. La referencia es Sandoval (1614):

"En los demás lugares iba cundiendo el fuego furiosamente, como si se hubieran concertado o se entendieran por atalayas y ahumadas, como suelen hacer en las costas y fronteras: así se movieron casi a un tiempo muchos lugares. En un memorial de León Picardo, criado del condestable y su pintor, leí que estando a la media noche cebando un azor en Burgos, hubo un tal terremoto y temblor de la tierra, que cayeron edificios y tejas, y los platos de las vaseras; y se le murió el azor de espanto, y movieron algunas preñadas." 
Fecha: Año 1520. Aparece indicada varias páginas antes del extracto de texto donde se recoge el temblor de tierra (Sandoval, 1614).

Hora: Medianoche, "a la media noche” (Sandoval, 1614).

Intensidad EMS-98: Medida únicamente a partir de la descripción de Sandoval (1614). Efectos en las personas: "se le murió el azor de espanto, y movieron algunas preñadas". Efectos en los objetos: "se cayeron los platos de las vaseras". Efectos en las edificaciones: “cayeron edificios y tejas”. El primer efecto indica que la vibración asustó a personas y animales, por lo tanto tendría intensidad mínima de V, ya que para valores de IV o menos, el nivel de vibración no asusta (EMS-98). Sin embargo, no se ha encontrado si se trata de una frase literal o una alegoría referida a un hecho real. El significado de la frase "movieron algunas preñadas" es discutible. La palabra preñada según el Diccionario de Autoridades (Real Academia Española, 1726-1739) es: "Se llama tambien la pared que está desplomada y forma una como barríga, por lo qual amenaza ruina." Esta descripción se puede referir al movimiento de paredes debido a las vibraciones. Por otro lado, ese mismo diccionario recoge la acepción de "mover" como abortar: "Significa assimismo parir antes de tiempo, o malparir..." Finalmente, se ha decidido no evaluar la intensidad basada en este hecho por su incertidumbre. Para el efecto en objetos, una intensidad mínima de V y máxima de VII explicaría la caída de los platos, dependiendo de la cantidad de objetos caídos (EMS-98). En la descripción dada dicha cantidad se desconoce, luego a partir de ese dato se le asigna un rango de intensidad entre V-VII. El valor de intensidad mínimo para la destrucción de un edificio de mampostería es de VII y una intensidad máxima de $\mathrm{X}$ ya que es donde todos los tipos de edificios de mampostería (A, B y C) sufren los mayores daños. Sin embargo del texto se entiende que no se produjo la caída de todos los edificios sino que de algunos sólo cayeron “tejas", luego el rango máximo no sería tan elevado. La unión de los efectos descritos estaría indicando que se trató de un temblor donde "cayeron edificios" (se entiende que no todos) y "tejas", además de "platos de las vaseras" y que la vibración asustó a las personas. Estos efectos descritos indican un valor de intensidad EMS-98 de VII.

\section{Oviedo 1522 (Oviedo 1522)}

En el catálogo del IGN se encuentra dicho terremoto basándose en tres referencias. La primera es Galbis (1940), cuya fuente es J. García Lomas. La segunda referencia es el catálogo de Mezcua \& Martínez Solares (1983), que lo recoge de la llamada Sección de Sismología e Ingeniería Sísmica del propio Instituto Geográfico Nacional. Existe una tercera referencia, sobre un trabajo llamado "Estudio de determinación de los datos sísmicos de base para las obras hidráulicas (1986, tomo II, Anejo 4, p.401)”, del Ministerio de Obras Públicas y Urbanismo. En este trabajo no ha sido posible encontrar las fuentes originales. Sin embargo, se han encontrado dos referencias nuevas. Este suceso fue recogido por Avilés (1590), cronista y canónigo de la catedral de Oviedo:

"Miércoles veinte y cinco días del mes de junio, año de mil quinientos veinte y dos tembló la tierra en esta ciudad (Oviedo), estando aquí el Capítulo de los frailes de San Francisco (...) Así mismo fue general este terremoto de temblar la tierra en todo este Principado e Reyno, e cayó en este terremoto mucha parte del monasterio de San Francisco de Avilés, que es de la Orden de San Francisco, e fue general en muchas partes de España, e cayeron muchos edificios".

Quadrado (1855) haciendo referencia al monasterio de San Francisco relató:

" $y$ aunque un terremoto en 25 de junio de 1522 derribó mucha parte del edificio, apenas se conoce alteración en su fábrica primitiva".

Fecha: El IGN indica junio de 1522, sin especificar el día. Sin embargo, se ha decidido respetar la referencia original Avilés (1590) y Quadrado (1855), 25 de junio de 1522 y así se ha modificado la fecha del IGN al añadir el día.

Intensidad EMS-98: Todos los efectos utilizados para calcular la intensidad han sido tomados de Avilés (1590) y Quadrado (1855). Efectos en las personas: Avilés (1590) "fue general este terremoto de temblar la tierra en todo este Principado e Reyno". Efectos en edificaciones: Avilés (1590) "cayeron muchos edificios cayó en este terremoto mucha parte del monasterio de San Francisco de Avilés”, Quadrado (1855) "apenas se conoce alteración en su fábrica primitiva". Los efectos en las personas estarían indicando que fue ampliamente percibido por la población, por tanto la intensidad mínima para este efecto 
sería de VI. En cuanto a los efectos en edificaciones, el monasterio de Francisco de Avilés (actual Iglesia de San Nicolás de Bari), de arquitectura románica, se trata de una edificación de mampostería, que por tanto tendría vulnerabilidad A-B. Para que cayese parte de la misma sin causar daños estructurales, según la descripción, se requeriría una intensidad mínima de VII y máxima de VIII. La caída de muchos edificios indicaría daños de grado 5 , luego una intensidad mínima de VIII y máxima de IX. Basándose en la descripción más detallada de los efectos en edificaciones, se podría relacionar con una intensidad de VIII-IX, ya que en ambos casos supondría la caída parcial o total de edificios con vulnerabilidad A y B.

\section{Castrotorafe (Zamora) Siglo XVI}

Es un terremoto nuevo no catalogado por el IGN ni por Ces Fernández (2015). La referencia proviene de Ruibal Rodríguez (2014):

"Será la inutilización del puente por un terremoto en el s. XVI lo que inicie la decadencia de esta población. [...]El hundimiento del puente por un terremoto en el s. XVI inició el declive [...] El castillo ha recibido alguna consolidación, el puente de doce arcos sólo conserva parcialmente sus pilares, bajo las aguas del pantano ”

Grado de credibilidad: Resulta destacable que sólo se haya encontrado la referencia tan actual de Ruibal Rodríguez (2014). No existen fuentes bibliográficas que respalden la teoría de la destrucción del puente por un terremoto. En los catálogos de Galbis (1932 y 1940) y el IGN no aparece ningún terremoto en Zamora a lo largo del siglo XVI. Por todo ello se trataría de un terremoto en discusión.

Intensidad EMS-98: Efectos en edificaciones: Ruibal Rodríguez (2014) "Será la inutilización del puente por un terremoto hundimiento del puente por un terremoto". Se trataría de un daño destructivo en una construcción de vulnerabilidad A o B, que se produce a partir de intensidad VIII. Por ello el rango de intensidad EMS-98 del terremoto es de VIII o superior.

\section{Vigo Siglos XVI-XVII}

Es un evento nuevo en el catálogo del IGN pero no para el catálogo de Ces Fernández (2015) quien obtiene la referencia de Taboada Leal (1840) el cual, a partir de un texto del último tercio del siglo XVII, cita temblores ocurridos en Vigo. Ces Fernández (2015) hace también referencia a Flórez (1767), escrito un siglo antes, de quién se recoge un texto similar.

Grado de credibilidad: En el texto de Taboada Leal (1840) se habla de varios posibles fenómenos naturales: "baja agora la marea... inundaciones de la mar... avenidas de las aguas de los montes, terremotos y tempestades". Todos estos efectos podrían asociarse de algún modo a un origen sísmico, sin embargo no es seguro que haya sido este fenómeno únicamente el causante de la destrucción. Además, no hay constancia de que exista el manuscrito del último tercio del siglo XVII desde donde Taboada Leal (1840) recoge el suceso (Ces Fernández, 2015), por ello, este terremoto ha sido catalogado en discusión.

Fecha: Se interpreta por el siglo en que fue escrito el manuscrito desde el cual Taboda Leal (1840) transcribió los hechos. Las ruinas aún se mantenían, en una ciudad poblada, por lo que es probable que sucediera poco antes (Ces Fernández, 2015). Flórez (1767) no indicó el año concreto.

Intensidad: Ces Fernández (2015) no da valor de intensidad, ya que la autora sólo utiliza la escala macro-sísmica EMS-98. Sería posible evaluarlo con la ESI-07; sin embargo los efectos descritos podrían no tener un origen exclusivamente sísmico.

\section{Monforte de Lemos (Lugo) 1604}

Nuevo para el catálogo del IGN. Ces Fernández (2015) describe los efectos de un terremoto ocurrido Monforte de Lemos (Galicia), cuya fuente es el libro I de bautismos, matrimonios y difuntos de la parroquia de Santa María de A Régoa, de esa localidad. También tomado de Ces Fernández (2015), Martínez Solares (2001) hace referencia a este terremoto.

Fecha: En la descripción original se habla de dos terremotos "al postero [=postrero] de mayo de mil seiscientos y quatr ${ }^{o}$ [=cuatro] a las siete de la mañana tembló el mundo, este mesmo ano el dia de [entoido] también tembló el mundo". Según Ces Fernández (2015) el "postrero" significa último, luego el 31/05/1604. La autora también determina que "entoido" se refiere a "entroido" o "antroido", forma gallega de denominar al carnaval. Siguiendo 
a Ces Fernández, en 1604 el martes de carnaval fue el 2 de marzo. Por tanto, al igual que Ces Fernández (2015), hemos considerado dos terremotos independientes, uno el 02/03/1604 y otro el 31/05/1604.

Intensidad EMS-98: Se ha añadido respecto al IGN, pero se ha modificado el valor de intensidad (IV-V) determinado por Ces Fernández (2015). El primero del 02/03/1604 se sintió más fuerte, ya que se transcribe "huimos el primer" [primero] que no el postrero”. En el caso del terremoto del 02/03/1604 para que la población huyera la intensidad mínima sería de $\mathrm{V}$, ya que algunas personas se asustan y corren al exterior. En el segundo 31/05/1604, la población no huyó pero fue sentido suponemos que ampliamente, por tanto se define de una intensidad de IV.

Temporalmente son dos terremotos muy seguidos. Tras el análisis de la intensidad se podría determinar que el segundo terremoto, ocurrido el 31/05/1604, por ser menos intenso, podría ser una réplica del terremoto del 02/03/1604.

\section{Valladolid 1605 (León 1605)}

La referencia original del catálogo del IGN y Ces Fernández (2015) proviene de Martínez Solares (2001). Se trata de una encuesta realizada después del terremoto de Lisboa de 1755, remitida por M. Franciso Josep de las Infantas desde Valladolid. Este texto se encuentra en el Archivo Histórico Nacional, encuesta 899, y ha sido transcrito por Martínez Solares (2001).

Fecha: Se ha modificado el día con respecto al catálogo del IGN. Ces Fernández (2015) razona acerca de un error en la transcripción de la fecha encontrado en el texto original. "Año de 1605, día 18 de Febrero, en que cayó la ceniza, a «las tres de la mañana, día de Carnes-tolendas, en la noche, para «amanecer dicho día de ceniza ". Según esta autora, el día de Carnes-tolendas sería el martes de carnaval, pero el día 18 de febrero de 1605 fue jueves. Dado que la Pascua cristiana se relaciona temporalmente con carnaval, la autora determina finalmente que el miércoles de ceniza de 1605 fue el 23 de febrero. En este trabajo hemos tomado esta fecha como válida. Ces Fernández relacionó este terremoto de 1605 con el de Monforte de Lemos de 1604, pero nosotros consideramos que fueron dos terremotos distintos.
Localización: Tal y como se indica en la transcripción original (Martínez Solares, 2001) los efectos se produjeron en Valladolid "fue cosa mui «notoria en Valladolid, y fuera de él", luego la localización se ubica en esta localidad. En el catálogo del IGN, dicho terremoto es asociado a León y no a Valladolid, de acuerdo a la descripción de Martínez Hernández (1994). No ha sido posible acceder a dicha referencia. Finalmente, se modifica la localización a Valladolid.

Intensidad EMS-98: se ha modificado la intensidad proporcionada por el IGN de IV-V. Efectos en las personas: "temblor de tierra mui grande. Los que estavan acostados le sintieron en sus «camas, los levantados le sentimos fue cosa mui «notoria en Valladolid, y fuera de él” (Martínez Solares, 2001). Del mismo modo, se encuentran efectos en los objetos: " todas «las Sillas se movieron, y se caieron los asientos ” (Martínez Solares, 2001). La intensidad mínima para que las personas tanto en el interior como en el exterior lo sientan y se asusten es de V. Sin embargo, que las sillas se muevan y se caigan los asientos estaría indicando una intensidad mínima de VI, ya que se consideran objetos pequeños de estabilidad normal. Por tanto se considera que tuvo una intensidad de VI.

\section{Pontevedra 1608}

Se trata de un terremoto no catalogado por el IGN pero sí por Ces Fernández (2015), quien toma la referencia de Fernández Cortizo (2006).

Fecha: Es imposible determinar el día o incluso el mes. La única referencia es que se "celebraron rogativas [...] en los meses de febrero y mayo" (Fernández Cortizo, 2006). Por tanto, se ha decidido fecharlo en el año 1608 tal y como se mostraba en Fernández Cortizo (2006).

Intensidad: No se ha conseguido dar un valor a la intensidad dada la ausencia de efectos descritos.

\section{Costas de Portugal 1612}

Se trata de un terremoto nuevo para el IGN y Ces Fernández (2015). La referencia proviene de González-Dávila (1771): "En este año en las tierras maritimas huvo grandes tempestades en la mar, muchos temblores. En la playa de Portugal 
perecieron más de sesenta naves. En Inglaterra murieron mas de dos mil personas. En la Italia, Alemania y Candia perecieron muchas gentes y edificios."

Grado de credibilidad: La catalogación en discusión tiene relación con las localidades afectadas por el suceso. No se menciona a España, pero al no saber la zona exacta de Portugal donde se produjo, no se descarta que también fuera afectada.

Fecha: Se indica en el título del capítulo que relata los acontecimientos: “Capitulo XLIX. Luis, Rey de Francia, embió por su Embaxador al Duque de Umene para disponer los tratados de su felicisimo casamiento con la Serenisima Infanta Doña Ana Mauricia. Año de 1612.”

Intensidad ESI-07: A pesar de que se describen efectos en los objetos "En la playa de Portugal perecieron más de sesenta naves" se relata un efecto probablemente asociado a un tsunami, valorable con la escala ESI-07. Para la destrucción de "más de sesenta naves" parece más precisa las características dadas para la intensidad VIII de la escala ESI-07 (Michetti et al., 2007), donde se habla de "pequeños tsunamis" y se precisa que "la escala métrica del oleaje anómalo comienza a partir de intensidad VII, siendo ya significativas (1-2 m) a partir de intensidad VIII." Por ello, se le asigna una intensidad ESI-07 de VIII.

\section{Oporto 1666 (Porto 1666)}

Es un terremoto catalogado por el IGN y Ces Fernández (2015). Este terremoto presenta seis referencias en el catálogo del IGN, destacando Galbis (1932) y Perrey (1847). La referencia de Perrey (1847) vendría de Von Hoff (1840).

Grado de credibilidad: En cuanto a su localización, Ces Fernández (2015) cuestiona que el terremoto de noviembre de 1666 se ubique en Oporto (Portugal). El motivo sería que cada vez que Von Hoff (1840) describe un terremoto en Oporto, lo describe como "Oporto in Portugal", por el contrario en este terremoto se dice "1666, im November. Erdstöße zu Corfu und Porto”, ubicándose en la ciudad de Corfu (Grecia) y "Porto" refiriéndose a Porta (Puerta). Según Albini (2004), citado por Ces Fernández (2015), la fuente original de Von Hoff (1840) revela un terremoto en Corfu (Grecia) y daños en Porta Rimenda, una de las puertas de entrada a esta ciudad, probablemente origen del error en Von Hoff (1840). Además, destaca la ausencia de referencias sobre este terremoto en trabajos anteriores de este mismo autor como en Von Hoff (1824). Por otro lado, Martínez Solares (com. pers.) considera que el terremoto de Oporto de noviembre de 1666 y el de diciembre de 1667 podrían ser el mismo.

Por ello, este terremoto se ha catalogado de erróneo.

Intensidad: No se mencionan efectos que permitan su evaluación.

\section{Oporto 1667}

Se trata de un terremoto nuevo respecto al catálogo IGN, pero ya catalogado por Ces Fernández (2015). La referencia viene en el catálogo de Galbis (1932) quien recoge el suceso de Perrey (1847), cuya fuente provenía de Von Hoff (1840) basándose en su anterior catálogo (Von Hoff, 1824).

Grado de credibilidad: en este caso, la descripción de Von Hoff (1840) indica claramente la ciudad de Oporto en Portugal "1667, im December. Erdbeben zu Oporto in Portugal”.

Intensidad: la ausencia de efectos descritos impide su evaluación.

\section{Mogadouro y Freixo de Espada à Cinta 1732}

Terremoto nuevo para el catálogo del IGN, pero catalogado por Ces Fernández (2015), que, citando a Abreu (2005), menciona un evento sísmico ocurrido alrededor de 1732 en la región de Tras-os-Montes. La información procede de los cuestionarios que fueron enviados tras el Terremoto de Lisboa de 1755 para la evaluación del mismo y otros eventos sísmicos (Ces Fernández, 2015). A la pregunta de si se recordaban temblores pasados y sus efectos, se encuentran las citas realizadas por varios curas de los siguientes núcleos rurales del Concelho de Mogadouro: Azinhoso el 1 de marzo de 1756, Macedo do Peso el 2 de marzo de 1756, Sanhoane el 26 de febrero de 1756, Tó el 5 de marzo de 1756 y Variz el 1 de marzo de 1756. Estos formularios se encuentran en el Archivo Nacional da Torre do Tombo (ANTT), 
Ministério do Reino, maço 638, Caixa 742, atado 3 y fueron transcritos por Ces Fernández (2015).

Zonas geográficas afectadas: La histórica región de Tras-os-Montes está situada al norte de Portugal y está formada por numerosos pueblos, entre ellos Mogadouro y Freixo de Espada à Cinta. Ces Fernández (2015) sitúa los efectos en dos villas específicas: Freixo de Espada à Cinta, localidad donde se ubica "na Igr[e]ja de Lagoaça" (parroquia de Macedo do Peso) que fue afectada por el terremoto y Mogadouro, de cuyas poblaciones rurales (Azinhoso, Macedo do Peso, Sanhoane, Tó y Variz) se recibieron las respuestas a los cuestionarios.

Intensidad EMS-98: Efectos en las personas: "Huyó la gente (cura de Macedo do Peso)”, “Hubo un terremoto en todas estas tierras...pero no duró tanto como el del primero de noviembre (cura de Sanhoane)". Efectos en edificaciones: "Tembló la Iglesia (cura de Macedo do Peso)", "Temblaron las casas pero no tanto como el primero de noviembre del pasado año (cura de Azinhoso)"y "ha habido un terremoto...pero tampoco causó daño alguno (cura de Tó)". Para sentirse que las casas temblaran pero sin causar daño alguno, se hablaría de una intensidad de entre IV-V ya que a partir de intensidad V se empiezan a producir daños moderados en los edificios. Sin embargo, el efecto sentido por la población de "huyó la gente" estaría indicando como dichas personas se asustaron y corrieron al exterior. Por tanto, este terremoto tendría una intensidad de V.

\section{Freixo de Espada à Cinta (Portugal) 1733}

Nuevo con respecto al catálogo del IGN, aunque catalogado por Ces Fernández (2015), se rescata un posible evento sísmico en Freixo de Espada à Cinta ocurrido en diciembre de 1733 (Abreu, 2005). También proviene de los cuestionarios enviados a diferentes lugares tras el terremoto de Lisboa, para la evaluación de éste y otros temblores (Ces Fernández, 2015). A pesar de que Abreu (2005) no recoja la descripción del cura de Avinhó que detalla el suceso, Ces Fernández (com. pers.), en investigaciones posteriores, ha conseguido hallar el texto, y nos ha facilitado la transcripción:

"em Freixo de Espada a Cinta, em Dezembro de 1733, segundo o cura de Avinhó” (Abreu, 2005)
Ces Fernández (com. pers.) también consiguió el fragmento al que hace referencia Abreu (2005), que fue transcrito de Themudo Barata et al., (1988):

“... E nam ha noticia que tenha havido outro, porem no anno de trinta, e tres estando na villa de Freixo de Espada à Cinta no mês de Dezembro houve outro porem menos, e nam fes dano algum..."

Grado de credibilidad: Ces Fernández (com. pers.) considera un posible error en la fecha que escribió el cura de Avinho, ya que el resto de localidades del Concelho de Mogadouro no describen este terremoto. Por tanto, podría tratarse del terremoto Algarve de diciembre de 1722 o del terremoto de Mogadouro y Freixo de Espada à Cinta (1732), siendo más probable que se tratase del segundo, al no encontrar referencias que describieran el terremoto de Algarve 1722 d.C. en la zona norte peninsular (Ces Fernández, com.pers.). En este trabajo se considera que la ausencia de descripciones en otras localidades no es motivo para su exclusión del catálogo. Por ello se cataloga como en discusión.

Intensidad EMS-98: "e nam fes dano algum..." (Themudo Barata et al., 1998). La ausencia de daños pero que haya sido sentido por la población, al haber sido catalogado, indica una intensidad EMS-98 de entre IV-V.

\section{Torre de Moncorvo (Portugal) 09/05/1751} (Aveiro 09/05/1751)

Terremoto presente en el catálogo del IGN pero no en Ces Fernández (2015). Sin embargo, en el catálogo del IGN este terremoto es localizado en Aveiro (Portugal). Su referencia inicial proviene del catálogo de Galbis (1932) cuya referencia es Sánchez-Navarro (1921). El IGN cataloga este terremoto como "falso" ya que se considera que SanchezNavarro (1921) pudo sacar la referencia de Perrey (1847), quien no describe dicho terremoto (Martínez Solares, com. pers.). En este trabajo se considera verídico puesto que Sanchez-Navarro (1921) pudo obtener la información de otra fuente, al no ser Perrey (1847) su única referencia (Udías, 2017).

Localización y zonas geográficas afectadas: Es necesario hacer una corrección en el catálogo del IGN donde se establece la localización en Aveiro. Buscando las fuentes originales de donde se ha tomado dicha información, se observa que no hay 
referencia a la localidad de Aveiro sino a Torre de Moncorvo (Galbis, 1932; Sánchez-Navarro, 1921). Por ello, se ha consignado Torre de Moncorvo como la localización del sismo y como zona afectada.

Intensidad: No se puede calcular dada la ausencia de descripción de los efectos.

Torre de Moncorvo (Portugal) 19/12/1751

(Torre de Moncorvo 19/12/1751)

Presente en el catálogo del IGN y de Ces Fernández (2015). La referencia inicial proviene del catálogo de Galbis (1932), quien cita dos fuentes: Perrey (1847) y Sánchez-Navarro (1921). Sin embargo este último autor relata que el terremoto fue en Aveiro y no en Torre de Moncorvo.

Para este evento, ha sido posible encontrar otra referencia, proporcionada en el catálogo de Ces Fernández (2015). Se trata del periódico la Gazeta de Lisboa Occidental (1751), que se hizo eco de la noticia. Además se ha encontrado que este terremoto fue catalogado por Ferrão et al., (2016).

Zonas geográficas afectadas: Dado que la mayoría de las fuentes hace referencia a daños producidos en Torre de Moncorvo, se ha considerado que el terremoto estaría ubicado en dicha localidad. Sin embargo, Sánchez-Navarro (1921) habla de Aveiro como localidad donde se sintió el terremoto. Por este motivo, se ha considerado como región afectada por el mismo.

Intensidad EMS-98: Efectos en las personas: "terremoto violento" (Perrey, 1847). Efectos en edificaciones: "En Torre Moncorvo derribó varias casas" (Galbis, 1932), "Varias casas dañadas en Torres de Moncorvo" (Perrey, 1847) y "Sacudiendo con ímpetu las casas..." (Gazeta de Lisboa Occidental, 1751). Considerando que las viviendas fueran de mampostería, para el colapso de varias casas sería necesaria una intensidad mínima de VII ya que se producirían daños de tipo 4 en algunos edificios de vulnerabilidad $\mathrm{A}$, mientras que en algunos edificios de vulnerabilidad $B$, el daño sería de tipo 3 o 2. Por otro lado, ya que no todos los edificios de vulnerabilidad A se han caído (Intensidad de IX) se podría dar un margen de máximo de intensidad VIII donde algunos edificios de mampostería colapsarían mientras que muchos seguirían en pie. Por tanto, se le ha dado un rango de intensidad entre VII-VIII.
Intensidad ESI-07: Se encuentran efectos asociados a nubes de polvo: “...salió de la misma sierra un gran vapor, e inmediatamente un viento, que duró por algunas horas. (Gazeta de Lisboa Occidental, 1751)”. Otro efecto es el de agitación de la vegetación: “...poniendo en acelerado movimiento a todos los árboles (Gazeta de Lisboa Occidental, 1751)”. En cuanto a la nube de polvo, se desarrolla a partir de intensidad VIII, por tanto este efecto nos estaría indicando una intensidad de VIII o superior. En lo que se refiere a la agitación de la vegetación, se observa con intensidades mínimas de VI siendo significativo a partir de VIII, cuando se rompen ramas y se pueden desenraizar árboles. Como estos efectos no han sido descritos, se le asigna una intensidad mínima de VI. Teniendo en consideración las nubes de polvo y la agitación de la vegetación, se puede establecer una intensidad ESI-07 de VIII o superior.

Los catálogos del IGN, Ces Fernández (2015) y Ferrão et al., (2016) dan un valor de intensidad VI al evento sísmico. En el anterior apartado se ha justificado un rango de intensidad EMS-98 de VII-VIII y un rango de VIII o superior en la escala ESI-07.

\section{Torre de Moncorvo (Portugal) enero 1752 (Torre de Moncorvo enero 1752)}

Presente en los catálogos del IGN y Ces Fernández (2015). Ambos catálogos citan como fuente a Galbis (1932), cuya referencia fue Perrey (1847) y de éste a su vez Von Hoff (1840). Según Ces Fernández (2015), el primero en citar tal evento fue Seyfart (1756).

Intensidad EMS-98: Se observan efectos en edificaciones: “...donde 600 casas, así como la iglesia se derrumbaron (Seyfart, 1756)”. Para producir el derrumbe de 600 casas se trataría de una intensidad mínima de IX, en la que muchos edificios de vulnerabilidad A (roca de cantera y adobe) y algunos de vulnerabilidad B (roca simple) sufren daños de colapso total o casi total. En cuanto al rango máximo, es destacable que no se habla de la destrucción total de la localidad por lo que edificios de roca masiva, o madera podrían haber quedado en pie (clases de vulnerabilidad C y D). Así la intensidad máxima sería de X. Por tanto estaríamos ante un terremoto de intensidad IX-X.

En el catálogo de Ces Fernández (2015), se propone que dicho terremoto podría ser una réplica del 
terremoto del 19 de diciembre de 1751, siendo tratado ambos como una unidad. En este trabajo se ha considerado que los efectos de destrucción de "600 casas" como de la "iglesia" estaría indicando una intensidad mayor (IX-X) que el terremoto de 19 de diciembre de 1751 (VII-VIII). Por ello, el terremoto de Torre de Moncorvo del 19 de diciembre de 1751 podría ser un precursor del terremoto de enero de 1752 ubicado en la misma localidad. Del mismo modo, podría haber relación causal entre ambos, de manera que el sismo del 19/12/1751 pudo haber desencadenado por transferencia de esfuerzos (stress triggering), el terremoto de enero de 1752.

\section{Discusión}

Tomando como base el catálogo del IGN, se han revisado, modificado y añadido parámetros de terremotos anteriores a 1755 en el noroeste peninsular atendiendo a las fuentes documentales primarias sobre ellos. Además se han incorporado nuevos terremotos no catalogados por el IGN. Si en los textos de referencia se describen efectos asociados al terremoto, se ha calculado la intensidad EMS98 y/o ESI-07. Todo ello para caracterizar mejor la sismicidad histórica y poder relacionarla con la sismicidad posterior a 1755.

\section{Terremotos revisados y modificados del catálogo del IGN}

En lo que se refiere a los terremotos ya existentes en el catálogo del IGN, se han revisado 189 parámetros y modificado un total de 26, explicados detalladamente en cada uno de los apartados (Tablas 2 y 3).

Tabla 3.-Parámetros totales revisados, modificados y nuevos. * tomado de Ces Fernández (2015). ${ }^{*}$ tomado de Ferrão et al., (2016).

\begin{tabular}{|c|c|c|c|}
\hline Parámetros & Nuevo & Revisado & Modificado \\
\hline Fecha & $14\left(10^{*}\right)$ & 7 & $6\left(1^{*}\right)$ \\
\hline Hora & $6\left(4^{\star}\right)$ & 2 & \\
\hline Localización & $14\left(10^{\star}\right)$ & 5 & $8\left(2^{*}\right)$ \\
\hline $\begin{array}{l}\text { Zonas geográficas } \\
\text { afectadas }\end{array}$ & $15\left(10^{\star}\right)$ & 2 & $10\left(3^{\star}\right)$ \\
\hline $\begin{array}{l}\text { Búsqueda de } \\
\text { nuevas referencias }\end{array}$ & $25\left(14^{\star}\right)$ & 2 & \\
\hline $\begin{array}{l}\text { Evaluación de la } \\
\text { intensidad }\end{array}$ & $16\left(1^{\star \star}\right)$ & & 2 \\
\hline
\end{tabular}

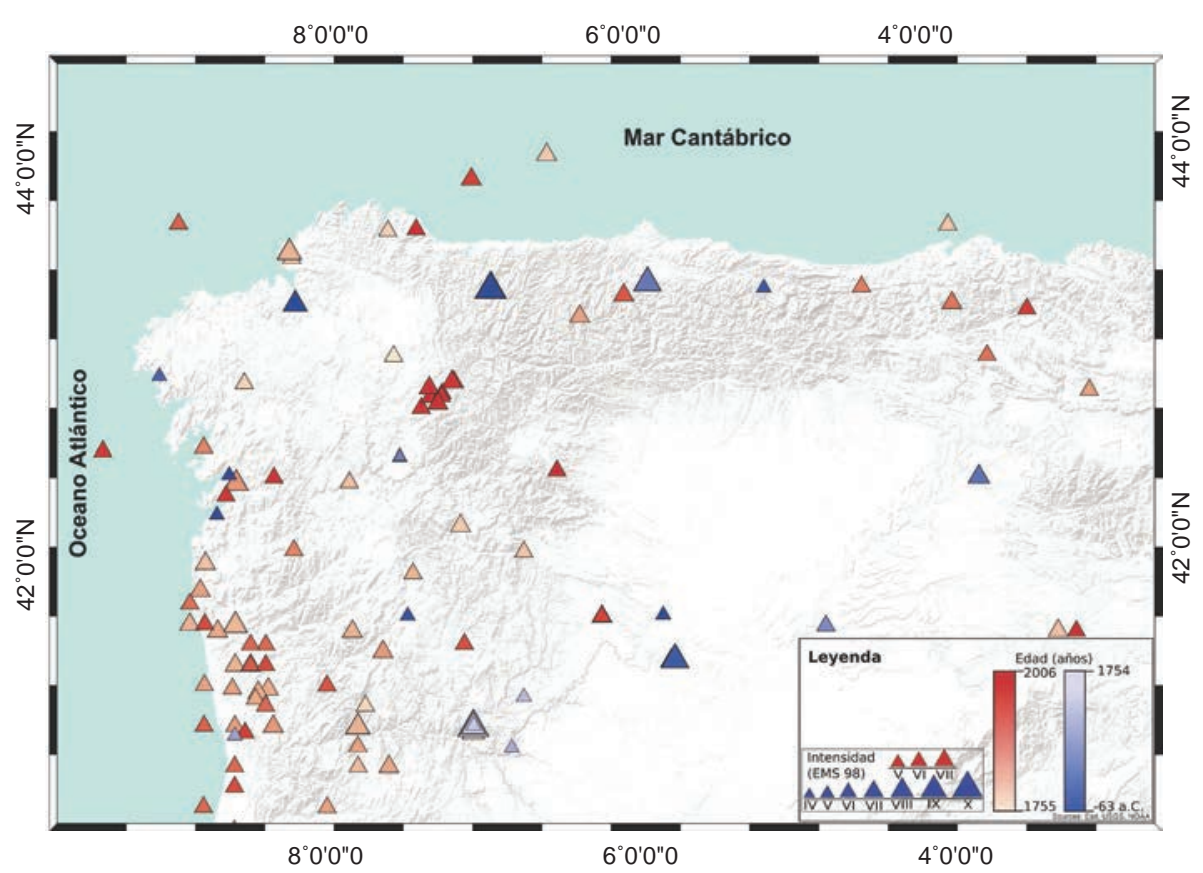

Figure 2.-Mapa con la localización de los terremotos del catálogo sísmico del NO peninsular (anteriores a 1755) estudiados en este trabajo (triángulos azules). Con triángulos rojos se muestran los terremotos posteriores a 1755 (catálogo IGN) con intensidad mayor o igual a V. 
En cuanto a la fecha, se realizaron las siguientes modificaciones (Tablas 1 y 2). El evento sentido en Italia y Europa en 217 a.C. considerado por el IGN de España 196 a.C. ha sido rectificado debido a que tuvo lugar durante la batalla del Lago Trasimeno (Italia), datada en el 217 a.C. (Goldsworthy, 2000). El terremoto de Norte de Portugal y Galicia del 63 a.C, se ha cambiado de fecha del 60 a.C. al 63 a.C. ya que en la referencia más antigua (Brito, 1597), se escribe año 63 a.C. Otro cambio de fecha importante es el realizado en el terremoto de Portugal 30 d.C, según el IGN del año 33 d.C. El suceso ocurrió “[... a los años dieciséis de su monarquía [...] imperio [...] Tiberio César" (Brito, 1609). De acuerdo a Rolfe (1913) el año dieciséis de su reinado se corresponde con el 30 d.C, por tanto, se modifica la fecha respecto el catálogo IGN. El terremoto en la provincia de Zamora 939 (W Península Ibérica 949) también ha sufrido modificación en la fecha. La referencia más antigua, "Chronicon Burgense", relata los hechos en el 939, por ello se ha modificado con respecto al catálogo del IGN. Además, según la descripción de "Anales Compostelanos” y "Chronicon Burgense” se añadió mes y día "terremoto del día $1^{\circ}$ de junio del 939”, coincidiendo con Ces Fernández (2015). El terremoto de Portugal 1309 según el IGN, se modificó a 1279 al indicarse "Era 1317" en la referencia original (Ces Fernández, 2015). El último cambio de fecha es en el terremoto de Oviedo del 25 de junio de 1522 donde se ha concretado el día gracias a las nuevas referencias (Avilés, 1590; Quadrado, 1855) aportadas en este trabajo.

Por otro lado, se han realizado modificaciones de la localización en 8 ocasiones (Tablas 2 y 3). Es destacable el caso del terremoto de la provincia de Zamora 939, localizado por el catálogo del IGN en el W de la Península Ibérica. Los motivos de la modificación de la localización a la provincia de Zamora son varios. Según Galbis (1940) este terremoto se produjo en la Cuenca del Duero; además los topónimos encontrados en las descripciones indican que en la provincia de Zamora se produjeron los mayores efectos (Cabrera, 1756; Flórez, 1767; Fernández Duro, 1882; Álvarez Martínez, 1889; Albarellos, 1919; Fernández-Prieto, 1953). Otro ejemplo es el terremoto de Valladolid de 1605, con ubicación en León de acuerdo al catálogo del IGN. En la transcripción original (Martínez Solares, 2001) se describen los efectos en Valladolid, mientras que el IGN basó la localización de León en un informe interno no publicado (Martínez Hernández, 1994) al que no hemos podido acceder. Por todo ello, se modifica la localización con respecto al IGN y se asigna a Valladolid. Un último ejemplo es la modificación realizada al terremoto de mayo de 1751 en Torre de Moncorvo, localizado en Aveiro según el IGN. Sin embargo, en las referencias originales tomadas por el IGN, no se habla de efectos en Aveiro sino en Torre de Moncorvo (Sánchez-Navarro, 1921; Galbis, 1932). Por ello, se ha corregido la localización a Torre de Moncorvo.

Por último, se han realizado 10 modificaciones en las zonas geográficas donde fue sentido el sismo, a partir de las nuevas referencias encontradas o revisando las ya existentes (Tablas 2 y 3). Ejemplo de ello es el terremoto del 63 a.C. establecido en el Norte de Portugal según el IGN. Referencias citadas por Ces Fernández (2015), previamente no consideradas por el IGN, citan al norte de Portugal, Galicia (Brito, 1597) y Betanzos (Martínez Santiso, 1892) como regiones donde se produjeron efectos por dicho evento. Por tanto, se incluye Galicia y la localidad de Betanzos como regiones afectadas. Un ejemplo de modificación al revisar las fuentes existentes, es el terremoto de Torre de Moncorvo de mayo de 1751. En la revisión de las referencias utilizadas por el IGN (Sánchez-Navarro, 1921; Galbis, 1932), se describe el terremoto en la localidad de Torre de Moncorvo y no en Aveiro. Por ello se modifica la zona afectada a Torre de Moncorvo.

Durante la revisión del catálogo del IGN se han encontrado terremotos ocurridos en Portugal, que tras la revisión de sus fuentes originales se ha comprobado que se ubican fuera de nuestra región a estudio. Éste sería el caso del terremoto ocurrido en el 346 d.C. en Portugal, cuya referencia proviene de Galbis (1940) y donde se dice: "fin tiempos del Emperador Theodosio tembló en la mayor parte de la redondez de la Tierra. Paulo Horatio dice que se separó el Continente portugués de las Islas Berlingas." Dichas islas se ubican muy alejadas de los márgenes de nuestra zona de estudio, luego no se ha seguido recabando información.

Tras el cálculo de la intensidad, y dada la proximidad espacial y temporal, se consideró una posible relación entre los terremotos de Torres de Moncorvo 
de diciembre de 1751 y de enero de 1752, ambos catalogados por el IGN. En el catálogo de Ces Fernández (2015), se propone que el terremoto de enero de 1752 podría ser una réplica del terremoto del 19 de diciembre de 1951. Tras la evaluación de la intensidad, se observa cómo el evento de 1752 tendría una intensidad EMS-98 mayor (IX-X) que el terremoto de 1751 (VII-VIII). Por consiguiente, se discute si el evento de 1751 pudo ser un precursor del terremoto de 1752. Del mismo modo, se podría pensar que se tratan de terremotos relacionados causalmente por transferencia de esfuerzos, de forma que el sismo de diciembre de 1751 pudo haber desencadenado el de enero de 1752.

La proximidad temporal hacen discutibles los terremotos de Monforte de Lemos de 1604. Tras analizar sus efectos, sugerimos que el del 2 de marzo tuvo una intensidad EMS-98 superior al del 31 de mayo, luego sería probable que el terremoto de mayo pudiera ser una réplica del de marzo.

\section{Eventos nuevos}

De un total de 27 eventos presentes en el catálogo elaborado en este trabajo, se han encontrado cuatro que no habían sido catalogados previamente (Tablas 1, 2 y 3). Cabe destacar que el IGN incluía 13, habiendo sido los 10 restantes aportados a partir del catálogo de Ces Fernández (2015).

De los cuatro eventos catalogados aquí, el más antiguo es el de Grandas de Salime (Asturias) del siglo II d.C, que gracias a las investigaciones arqueológicas llevadas a cabo por Ángel Villa Valdés en 2009, se describe como "un terremoto devastó el centenario poblado". Los efectos descritos nos llevan a establecer una intensidad entre IX-X para dicho terremoto. El segundo es el sismo ocurrido de Burgos en 1520, del que Sandoval (1614) describe efectos en personas, objetos y edificaciones, que nos permiten otorgarle una intensidad de VII. El tercero de los nuevos terremotos corresponde al ocurrido en Castrotorafe (Zamora) en el Siglo XVI. De acuerdo a los textos de Ruibal-Rodríguez (2014) se describen efectos de hundimiento de un puente, otorgándose un rango de intensidad EMS-98 de VIII o superior. El cuarto de los temblores nuevos catalogados, corresponde a un evento en las costas de Portugal en 1612 descrito por González-Dávila (1771), fuente habitual de Galbis (1932) pero que no había sido catalogado. Finalmente, se le otorga una intensidad de VIII en la escala ESI-07 al describir lo que interpretamos como un pequeño tsunami.

\section{Evaluación de la intensidad}

El cálculo de la intensidad ha sido uno de los objetivos de este trabajo, ya que su homogeneización permite comparar estos eventos históricos con los posteriores a 1755. Se han revisado todas las intensidades en base a los documentos originales y han sido calculadas con dos escalas; EMS-98 y ESI-07 (Tablas 1 y 2). De los 27 eventos sísmicos catalogados, a 15 se le ha podido otorgar una intensidad según la escala EMS-98, 14 intensidades calculadas en este trabajo y una intensidad (Coimbra 1347) tomada de Ferrão et al. (2016). Con la intensidad ESI-07 han sido medibles seis terremotos, de los cuales tres se han podido catalogar con las dos escalas (Norte de Portugal 63 a.C.; Zamora 939 d.C. y Torre de Moncorvo diciembre de 1751) (Tablas 1 y 2).

En lo que se refiere a la escala EMS-98, se ha catalogado la intensidad entre valores de IV (Portugal 1279, Monforte de Lemos 31/05/1604 y Freixo de Espada à Cinta 1733) hasta valores de entre IX-X (Grandas de Salime, siglo II y Torre de Moncorvo, 1752) (Tablas 1 y 2). Para evaluar la intensidad con la EMS-98, se han encontrado efectos en personas, por ejemplo en el Norte de Portugal, 63 a.C.: “...ivan huyendo las personas a las montañas, tratando cada uno tanto de si solo, que ni los maridos se acordaban de las mujeres, ni ellas de los hijos; ni alguno de otra cualquier obligacion o interés" (Brito, 1597; Faria y Sousa, 1678); Portugal 1279 d.C.: "un temblor, de tierra espantosa" (Brandam, 1672); Monforte de Lemos 1604 d.C.: "huimos el primer ${ }^{\circ}$ [primero] que no el postrero" (Ces Fernández, 2015) y Valladolid 1605 d.C.: "temblor de tierra mui grande...Los que estavan acostados le sintieron en sus camas, los levantados le sentimos...fue cosa mui notoria en Valladolid, y fuera de él" (Martínez Solares, 2001). También se han encontrado efectos en objetos: Grandas de Salime siglo II: "hallazgo sobre los suelos públicos de joyas y monedas... abundancia de ajuares domésticos bajo las ruinas" (Villa-Valdés, 2009), Burgos 1520 d.C.: "se cayeron los platos de las vaseras" 
(Sandoval, 1614) y Valladolid 1605 d.C.: “...todas las Sillas se movieron, y se caieron los asientos..." (Martínez Solares, 2001). Los efectos más ampliamente catalogados para esta escala son los daños en edificaciones, como es el caso de los terremotos de Norte de Portugal 63 a.C.: "arruinó muchos edificios, y lugares enteros" (Moreira de Mendonça, 1758); Grandas de Salime siglo II d.C.: "el brutal desplome, de una vez, de grandes muros...un terremoto devastó el centenario poblado" (Villa-Valdés, 2009); Burgos 1520 d.C.: "cayeron edificios" (Sandoval, 1614); Oviedo 1522 d.C.: "cayeron muchos edificios... cayó en este terremoto mucha parte del monasterio de San Francisco de Avilés." (Avilés, 1590); Castrotorafe siglo XVI: "El hundimiento del puente por un terremoto en el s. XVI inició el declive...” (RuibalRodríguez, 2014) y Torres de Moncorvo (diciembre de 1751): "En Torre Moncorvo derribó varias casas" (Galbis, 1932). Se han considerado las incertidumbres en la vulnerabilidad de las construcciones, evaluando el posible rango de intensidad mínima a máxima compatible con los efectos descritos.

La escala ESI-07 presenta valores que oscilan desde un mínimo de VII (A Coruña 1217) hasta un máximo de XI del terremoto de Zamora del 939 d.C (Tablas 1 y 2). En esta escala los efectos medidos han sido tsunamis, como en el Norte de Portugal 63 a.C.: "Y el mar saliendo en algunas partes de sus ordinarios límites, ocupó mucha parte de la tierra, dejándola en otros lugares descubierta" (Brito, 1597; Faria y Sousa, 1678; Moreira de Mendonça, 1758) o en las Costas de Portugal 1612 d.C.: "En la playa de Portugal perecieron más de sesenta naves” (González-Dávila, 1771). Además, agrietamientos y fracturación del terreno en el terremoto Portugal 30 d.C.: "Se mostraban rocas abiertas de este terremoto" (Brito, 1609), movimientos de ladera en el terremoto de A Coruña 1217 "pérdida de nivel de la montaña, que al hundirse de un lado [...] perdió la elevada montaña el equilibrio, desplomándose sobre el estrecho valle" (Barros, 1885), nubes de polvo en el terremoto de Torre de Moncorvo de diciembre de 1751: “...salió de la misma sierra un gran vapor, e inmediatamente un viento, que duró por algunas horas.” (Gazeta de Lisboa Occidental, 1751) y agitación de la vegetación en el terremoto de Torre de Moncorvo de diciembre de 1751: “...poniendo en acelerado movimiento a todos los árboles” (Gazeta de Lisboa Occidental, 1751).

\section{Relación con la sismicidad posterior a 1755}

La sismicidad en la Península Ibérica se encuentra principalmente asociada al margen sur peninsular (Figs. 1 y 2). La región objeto de estudio acumula una parte de esa deformación transmitida intraplaca cuyo resultado es la sismicidad observada (Villamor et al., 2012; Martín-González et al., 2012). Para representar los eventos históricos aquí catalogados (Figs. 1 y 2) se ha tomado el valor concreto asignado o el valor máximo en el caso de haber asignado un rango a la intensidad EMS-98. En el noroeste peninsular es posible observar una sismicidad histórica importante (Fig. 1), destacando Galicia y norte de Portugal con mayores eventos registrados. En Galicia se ubican los terremotos de: Betanzos (63 a.C.), Grandas de Salime (siglo II), Galicia (451 d.C. y 454 d.C.), A Coruña (1217 d.C.), Vigo (siglo XVIXVII), Monforte de Lemos (1604 d.C) y Pontevedra (1608 d.C.). En el norte de Portugal es posible localizar eventos en Mogadouro y Freixo da Espada à Cinta (1732), Freixo de Espada à Cinta (1733) y Torre de Moncorvo (1751 y 1752). Hay que señalar que en la representación de terremotos históricos no se encuentran terremotos como el del 217 a.C. ya que su localización carece de precisión suficiente al situarse genéricamente en Italia y Europa. Por el mismo motivo, tampoco se han incluido los terremotos de Portugal 30 d.C., Portugal 1279 d.C. y Costas de Portugal 1612 d.C.

Si la distribución geográfica de la sismicidad histórica (anterior a 1755) se compara con los terremotos del catálogo del IGN posteriores a 1755, (Fig. 2), se observa como los terremotos históricos se ubican próximos a los posteriores a 1755. Para su análisis (Fig. 2), se representan los terremotos posteriores a 1755 con intensidad EMS-98 mayor a V y terremotos históricos (anteriores a 1755) que poseen un valor de intensidad EMS-98 asignado en este trabajo. Se debe tener en consideración que dichos eventos históricos presentan una incertidumbre importante en su localización, que es creciente con el paso del tiempo (López-Fernández et al., 2004; López-Fernández, 2008; Martin-González et al., 2012; González, 2017). Aún así, la figura 2 muestra cómo la sismicidad más reciente tiene precedentes históricos en el noroeste peninsular, y por tanto no es anómala. 
Desde el punto de vista de la intensidad antes de 1755 , se han registrado intensidades en la escala EMS-98 que van desde IV hasta un máximo de $\mathrm{X}$, mientras que con posterioridad a 1755 la intensidad máxima registrada ha sido de VII. Esta diferencia en las intensidades puede explicarse por una actividad histórica más importante que la registrada con posterioridad a 1755 o por una mayor ventana de observación temporal de la sismicidad histórica.

En esta región intraplaca se requieren catálogos lo más completos posible, lo cual se perfeccionaría con posteriores estudios de sismicidad histórica y paleosismología. Por ello, futuros estudios paleosísmicos y de tectónica activa deberían prestar atención a fallas sismogénicas que puedan ser activas bajo el régimen tectónico actual y que puedan deslizar bajo un régimen normal o de desgarre, que es el propuesto para esta región intraplaca (Stich et al., 2003; Vicente et al., 2008; Martin-González et al., 2012).

\section{Conclusiones}

En este trabajo se ha estudiado la sismicidad en el noroeste peninsular (Galicia, Asturias, Cantabria, Castilla y León y norte de Portugal), que se encuentra principalmente sobre un basamento varisco, considerada tradicionalmente como una zona sísmicamente estable y donde resulta complejo realizar estudios de actividad tectónica reciente, entre otros motivos por la escasez de sedimentos mesozoicos y cenozoicos que permitan datar la actividad de las fallas. Sin embargo, esta región intraplaca presenta una relevante sismicidad instrumental (p. ej. series sísmicas de Sarria-Triacastela-Becerreá de los años 1995 y 1997, con terremotos de magnitud hasta 5.3), lo que unido a la escasez de registros históricos en la zona, plantea la problemática del significado de esta sismicidad intraplaca en una región considerada sísmicamente estable.

Para caracterizar mejor la sismicidad se ha realizado la revisión y ampliación de los catálogos sísmicos de esta región intraplaca anteriores a 1755 (periodo peor documentado del catálogo sísmico), cuyo resultado es un nuevo catálogo sísmico con 27 terremotos. Esta revisión se ha realizado sobre fuentes documentales primarias. Este trabajo recoge un total de 27 terremotos anteriores a 1755 que afectaron el noroeste peninsular, ampliando el catálogo del Instituto Geográfico
Nacional que documenta 13 eventos localizados en esa zona de estudio durante ese periodo. Del trabajo de Ces Fernández (2015) se han incorporado 10 eventos no documentados previamente por el catálogo del IGN. Además, en este trabajo se han catalogado 4 terremotos nuevos no incluidos en ninguno de estos catálogos previos (Tablas 1 y 2). De un total de 189 parámetros revisados del catálogo oficial, se han modificado 26 de ellos (donde se incluye fecha, localización, zonas geográficas donde se sintió el terremoto e intensidad) y ampliado 65 parámetros (fecha, hora, localización, zonas geográficas, y cálculo de la intensidad) (Tabla 3).

Del mismo modo, en este trabajo se ha evaluado la intensidad con las escalas EMS-98 y ESI-07 para los terremotos históricos catalogados, siguiendo las descripciones de las fuentes primarias. Con respecto al total, se ha evaluado una intensidad EMS-98 a 15 terremotos, y a 6 eventos con la escala ESI-07 (Tabla 1). En la escala EMS-98 se han registrado terremotos desde una intensidad mínima de IV (Portugal, 1279, Monforte de Lemos, mayo de 1604 y Freixo de Espada à Cinta, 1733), hasta una intensidad de X (Grandas de Salime, siglo II y Torre de Moncorvo, 1752) (Tabla 1), mientras que la intensidad calculada en la escala ESI-07 es de VII (A Coruña, 1217) a XI (Zamora, 939) (Tabla 1).

La zona de estudio ha sido objeto de una sismicidad histórica remarcable, destacando la actividad producida en Galicia y norte de Portugal. En Galicia se localizan los terremotos del 63 a.C., Siglo II, 451, 454, 1217, siglo XVI-XVII, 1604 y 1608. En el norte de Portugal es posible localizar eventos en los años 1732, 1733, 1751 y 1752. Se ha comparado esta sismicidad histórica con la posterior a 1755 (Fig. 2), observándose como los epicentros presentan una similitud en su distribución espacial. Si se compara la intensidad EMS-98 entre los dos periodos, la intensidad previa a 1755 (Tabla 1) presenta valores en EMS-98 de IV-X, mientras que la máxima intensidad posterior a 1755 en la escala EMS-98 es de hasta VII (Fig. 2). A la vista de los resultados se observa cómo históricamente han existido terremotos de igual o mayor intensidad que los actuales. Por tanto la sismicidad desde mediados del siglo XVIII no sería anómala en esta región.

En zonas intraplaca, con largos periodos de recurrencia, los catálogos deben completarse lo más 
posible para poder recoger la actividad completa de las fallas. En estas regiones es necesario un esfuerzo mayor en ampliar el catálogo sísmico por medio de estudios de sismicidad histórica e instrumental y paleosismología. Por ello futuros estudios deberían prestar atención a fallas sismogénicas que puedan ser activas bajo el régimen tectónico actual y que puedan deslizar bajo un régimen normal o de desgarre, que es el propuesto para esta región intraplaca.

\section{AGRADECIMIENTOS}

Este trabajo ha sido financiado dentro de los proyectos del Ministerio de Economía y Competitividad y Union Europea (MINECO-FEDER) CGL2015-70970-P y CGL2011-14925-E, además de la beca de la Comunidad de Madrid del Fondo Social Europeo (PEJD-2017-PRE/AMB-3472). Agradecer a los revisores Dr. Álvaro González de la Universidad de Zaragoza y al Dr. Jose Jesús Martínez Díaz, de la Universidad Complutense de Madrid, los comentarios y sugerencias que han permitido mejorar el manuscrito. Además, al Dr. José Manuel Martínez Solares del IGN y a la Dra. Begoña Ces Fernández, agradecerles toda la información proporcionada y los comentarios realizados.

\section{Referencias}

Abreu, C. de (2005). O Terremoto de 1755 na zona oriental de Tras-os-Montes: Contributo para as comemorações do $250^{\circ}$ aniversario desse desastre natural. El Filandar-O Fiadeiro, 16: 3-25.

Albini, P. (2004). A survey of the past earthquakes in the Eastern Adriatic (14th to early 19th century). Annals of Geophysics, 47 (2-3): 675-703.

Albarellos, J. (1919). Efemérides burgalesas, prólogo por Eloy García de Quevedo. Diario de Burgos, Burgos, $281 \mathrm{pp}$.

Al-Himyari (1963). Kitab ar-Rawd al-Mitar. Traducido por Ma . del Pilar Maestro González. Valencia, 437 pp.

Álvarez Martí-Aguilar, M. (2017). Terremotos y tsunamis en Portugal en época antigua: el legado de Bernardo de Brito y su Monarchia Lusytana (1597-1609). Euphrosyne, 45: 183-204.

Álvarez Martínez, U. (1889). Historia general civil y eclesiástica de la provincia de Zamora. La Seña Bermeja, Zamora, 457 pp.

Avilés, T. de (1590). Armas y linajes de Asturias y antigüedades del Principado. $214 \mathrm{pp}$.

Barros, R. (1885). Historia de los terremotos de Andalucía III. Revista popular de conocimientos útiles. 18(228).

Bernárdez Vilar, X. (2004). Idacio Lémico, Chronica (379-439). Santiago de Compostela: Xunta de Galicia. Dirección Xeral de Política Lingüística, A Coruña, 183 pp.
Brandam, F. (1672). Sexta parte da Monarchia Lusitana: que contem a histoira dos ultimos vinte \& tres annos del Rey Dom Dinis. Lisboa, 548 pp.

Brito, F.B. (1597). Monarchia Lusitana. Parte primeira que contem as historias de Portugal desde a criação do mundo te o nacimento de nosso señor Iesuchristo. Alcobaça, 877 pp.

Brito, F.B. (1609). Monarchia Lusitana. Segunda parte em que se continuão as historias de Portugal desde o nacimento de nosso Salvador Jesu Christo, ate ser dado em dote ao Conde dom Henrique. Lisboa, $602 \mathrm{pp}$.

Cabrera, M. (1756). Explicacion physico-mechanica de las causas del temblor de tierra. Sevilla, 55 pp.

Carré-Aldao, E. (1936). Geografía general del Reino de Galicia. Ediciones Gallegas, A Coruña, Vols. 4, 5 y 6.

Ces Fernández, B. (2015). Los efectos del seísmo de Lisboa de 1755 sobre el patrimonio monumental de Galicia. Volumen III: Anexo. Repertorio de seísmos sentidos en Galicia entre los años 377 a.C. y 1855. Tesis doctoral, Universidade Da Coruña, 842 pp.

Chías Navarro, P. \& Abad Balbo, T. (2008). La construcción del territorio: caminos y puentes en Castilla y León. En: Historia de las Obras Públicas en Castilla y León: Ingeniería, Territorio y Patrimonio. CICCP Junta de Castilla-León, Valladolid, 299-414.

Comité Européen de Normalisation -CEN-. (2004). Eurocode 8, design of structures for earthquake resistance-part 1: general rules, seismic actions and rules for buildings. European Standard BS EN 1998-1, Brussels, 229 pp.

Conde, J.A. (1840). Historia de la dominación de los árabes en España, sacada de varios manuscritos y memorias arábigas. París, 336 pp.

Cuervo Álvarez, B. (2015). Asturias prerromana. Castro del Chao Samartín. Historia Digital, 15(25): 92-108.

Faria y Sousa, M. de (1678). Europa portuguesa. Segunda edición correcta, ilustrada, y añadida en tantos lugares, y con tales ventajas que es labor nueva. Tomo I, Lisboa, 508 pp.

Fernández-Cortizo, C. (2006). ¿En Galicia, el hambre entra nadando? Rogativas, clima y crisis de subsistencias en la Galicia litoral sudoccidental en los siglos XVI-XVIII. In: Muerte y ritual funerario en la historia de Galicia (Rodríguez-Casal, A.A. \& González-Lopo, D.L., Eds.), Universidad de Santiago de Compostela, Santiago de Compostela, 259-298.

Fernández Duro, C. (1874). Antigüedades romanas de la provincia de Zamora. La ilustración española y americana, 16 (30 de abril): 246-247; 17 (8 de mayo): 262-263; 22 (15 de junio): 343 y 346-347.

Fernández Duro, C. (1882). Terremoto en el siglo X. La ilustración española y americana, 46 (15 de diciembre): 367-368.

Fernández-Prieto Domínguez y Losada, E. (1953). Nobleza de Zamora. Consejo Superior de Investigaciones Científicas, Madrid, 915 pp. 
Ferrão, C.; Bezzeghoud, M.; Caldeira, B. \& Borges, J.F. (2016). The seismicity of Portugal and its adjacent Atlantic Region from 1300 to 2014: Maximum observed intensity (MOI) Map. Seismological Research Letters, 87 (3): 743-750. https://doi. org/10.1785/0220150217

Flórez, E. (1767). España sagrada: theatro geographico-historico de la iglesia de España. Continuacion de las memorias de la santa iglesia de Tuy y coleccion de los chronicones pequeños publicados e ineditos de la historia de España. Madrid, 23.

Fontana-Tarrats, J.M. (1977). Historia del clima del FinisTerrae Galaico. Madrid, 127 pp.

Galadini F.; Hinzen K.G. \& Stiros S. (2006) Archaeoseismology: Methodological issues and procedure. Journal of Seismology, 10: 395-414, https://doi. org/10.1007/s10950-006-9027-x

Galbis Rodríguez, J. (1932). Catálogo sísmico de la zona comprendida entre los meridianos $5^{\circ}$ E. y $20^{\circ} \mathrm{W}$. de Greenwich y los paralelos $45^{\circ}$ y $25^{\circ} \mathrm{N}$. Tomo I. Dirección General del Instituto Geográfico, Catastral y de Estadística Madrid, 567 pp.

Galbis Rodríguez, J. (1940). Catálogo sísmico de la zona comprendida entre los meridianos $5^{\circ}$ E. y $20^{\circ} \mathrm{W}$. de Greenwich y los paralelos $45^{\circ}$ y $25^{\circ} \mathrm{N}$. Tomo 2, Talleres del Instituto Geográfico y Catastral, Madrid.

García-Mayordomo, J.; Insua-Arévalo, J.M.; MartínezDíaz, J.J.; Jiménez-Díaz, A.; Martín-Banda, R., Martín-Alfageme, S., Álvarez-Gómez, J.A., Rodríguez-Peces, M.; Pérez-López, R.; Rodríguez-Pascua, M.A.; Masana, E.; Perea, H.; Martín-González, F.; Giner-Robles, J.; Nemser, E.S.; Cabral, J. \& QAFI compilers. (2012). The Quaternary Active Faults Database of Iberia (QAFI v.2.0). Journal of Iberian Geology 38 (1): 285-302. https://doi.org/10.5209/ rev_JIGE.2012.v38.n1.39219

García Pérez, G. (1994). Covadonga, un mito nacionalista de origen griego. El Basilisco: Revista de filosofía, ciencias humanas, teoría de la ciencia y de la cultura,

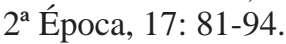

Gasperini, P.; Bernadini, F.; Valensise, G. \& Boschi, E. (1999). Defining seismogenic sources from historical earthquake felt reports. B Seismol Soc Am, 89: 94-110.

Gazeta de Lisboa Occidental (28 de diciembre de 1751). Número 52.

Goldsworthy, A. (2000). Grandes Batallas. Las Guerras Púnicas. Ed. Ariel, Barcelona, 448 pp.

González, Á. (2017) The Spanish National Earthquake Catalogue: Evolution, precision and completeness. J Seismol, 21 (3): 435-471. https://doi.org/10.1007/ s10950-016-9610-8

González-Dávila, G. (1771). Monarquía de España. Historia de la vida y hechos del ínclito monarca, amado y santo Don Felipe Tercero. Tomo 3, Joachin de Ibarra impresor de Cámara de S.M, Madrid.
Grünthal, G. (1998). European Macroseismic Scale 1998. European Seismological Commission, Luxemburg, $101 \mathrm{pp}$.

Gruppo di lavoro CPTI (2004). Catalogo Parametrico dei Terremoti Italiani, versione 2004 (CPTI04). INGV, Bologna. http://doi.org/10.6092/INGV.IT-CPTI04

Guéneau de Montbeillard, P. (1761). Liste chronologique des éruptions de volcans, tremblements de terre, faits météorologiques les plus remarquables, des cometes, des maladies pestilentielles, \&c. jusqu'en 1760. Tirée des Mémoires des Académies de l’Europe, des Ouvrages périodiques, des Histoires générales \& des Relations particulieres. En: Collection Academique composée des mémoires, actes ou Journaux des plus célébres Académies \& Sociétés Littéraires Étrangères, des Extraits des meilleurs Ouvrages Périodiques, des Traités particuliers, \& des Piéces Fugitives les plus rares (Desventes, F.; Desaint, J.; Saillant, C.; Ganeau, L.E; Guillyn, P. y Lambert, M., Eds.), Tome 6, Paris, 488-675.

Guidoboni, E. \& Ebel, J.E. (2009). Earthquakes and Tsunamis in the Past: A Guide to Techniques in Historical Seismology. Cambridge University Press, 590 pp.

IAEA (2010). Seismic Hazards in Site Evaluation for Nuclear Installations. International Atomic Energy Agency IAEA Safety Standards, No. SSG-9, 80 pp.

IAEA (2015). The contribution of palaeoseismology to seismic hazard assessment in site evaluation for nuclear installations. International Atomic Energy Agency IAEA-TECDOC series 1767, 208 pp.

IGN - Instituto Geográfico Nacional (2018). Base de Datos macrosísmica (hasta el año 1900). www.ign. es/web/ign/portal/sismicidad-historica

Korjenkov, A.M. \& Mazor, E. (2013). The features of the earthquake damage patterns of ancient city ruins in the Negev Desert, Israel. Geotectonics, 47: 52-65. http://dx.doi.org/10.1134/S0016852113010032.

López-Fernández, C. (2008). Actividad sísmica, zonación sismotectónica y riesgo sísmico en el NO de la Península Ibérica. Tesis doctoral, Universidad de Oviedo, 267 pp.

López-Fernández, C.; Pulgar, J.A.; Gallart, J.; González, J.M.; Díaz, J.; M. Ruiz. (2004). Actividad sísmica en el noroeste de la Península Ibérica observada por la red sísmica local del Proyecto GASPI (1999-2002). Trabajos de Geología, 24: 91-106.

Mackey, B.H. \& Quigley, M.C. (2014). Strong proximal earthquakes revealed by cosmogenic $3 \mathrm{He}$ dating of prehistoric rockfalls, Christchurch, New Zealand. Geology, 42: 975-978. https://doi.org/10.1130/G36149.1

Mallet, R. (1862). Great Neapolitan Earthquake of 1857. The First Principles of Observational Seismology. Chapman and Hall, London, 831 pp.

Mariana, J. de (1828). Historia General de España (Tomo II). Madrid, 602 pp.

Mariana, J. de (1840). Historia General de España (Tomo X). Barcelona, 585 pp. 
Martín, J.C. (2009). Los Annales Castellani Antiquiores y Annales Castellani Recentiores. In: Territorio, sociedad y poder. Oviedo (España), 203-226.

Martín-González, F. (2005). Tectónica alpina, neotectónica y sismotectónica en la terminación occidental de los relieves cantábricos (Macizo Ibérico). Marco tectónico de las crisis sísmicas de Lugo. Tesis doctoral, Universidad Complutense. Madrid, 313 pp.

Martín-González, F. (2009). Cenozoic tectonic activity in a Variscan basement: Evidence from geomorphological markers and structural mapping (NW Iberian Massif). Geomorphology, 107: 210-225. https://doi. org/10.1016/j.geomorph.2008.12.008

Martín-González, F. (2018). Earthquake damage orientation to infer seismic parameters in archaeological sites and historical earthquakes. Tectonophysics, 724-725: 137-145. https://doi.org/10.1016/j.tecto. 2018.01.013

Martín-González, F. \& Heredia, N. (2011). Geometry, structures and evolution of the western termination of the Alpine-Pyrenean Orogen relief (NW Iberian Peninsula). Journal of Iberian Geology, 37: 102-120. https://doi.org/10.5209/rev_JIGE.2011.v37.n2.1

Martín-González, F.; Antón, L.; Insua-Arévalo, J.M.; Vicente, G. de; Martínez-Díaz, J.J.; Muñoz-Martín, A.; Heredia, N. \& Olaiz, A. (2012). Seismicity and potentially active faults in the Northwest and Central-West Iberian Peninsula. Journal of Iberian Geology, 38: 53-69. https://doi.org/10.5209/rev_ JIGE.2012.v38.n1.39205

Martín-González, F.; Freudenthal, M.; Heredia, N.; Martín-Suárez, E. \& Rodríguez-Fernández, R. (2014). Palaeontological age and correlations of the Tertiary deposits of the NW Iberian Peninsula: the tectonic evolution of a broken foreland basin. Geol. J., 49 (1):15-27. https://doi.org/10.1002/gj.2484

Martín-Serrano, A.; Mediavilla, R. \& Santisteban, J.I. (1996). North-western Cainozoic record: present knowledge and the correlation problem. In: Tertiary basins of Spain: The Stratigraphic Record of Crustal Kinematics (Friend, P.F. \& Dabrio, C.J., Eds.), Cambridge University Press, 237-246. https://doi. org/10.1017/CBO9780511524851.033

Martínez-Díaz, J.J.; Capote, R.; Tsige, M.; Villamor, P.; Martín-González, F. \& Insua-Arévalo, J.M. (2006). Seismic triggering in a stable continental area: The Lugo 1995-1997 seismic sequences (NW Spain). Journal of Geodynamics, 41: 440-449. https://doi. org/10.1016/j.jog.2006.01.001

Martínez Hernández, M. L. (1994). Información sobre sismicidad contenida en el fichero climático de José María Fontana Tarrats (Instituto Nacional de Meteorología). Instituto Geográfico Nacional, Informe interno.

Martínez-Santiso, M. (1892). Historia de la ciudad de Betanzos. Sucesores de Castañeira (Eds.). Betanzos, 476 pp.
Martínez Solares, J.M. (2001). Los efectos en España del terremoto de Lisboa. Monografía 19, Instituto Geográfico Nacional, Madrid, 756 pp.

Martínez Solares, J.M. \& Mezcua Rodríguez, J. (2002). Catálogo sísmico de la península ibérica (880 a.C. 1900). Monografía 18, Instituto Geográfico Nacional, Madrid, 256 pp.

Martins, I. \& Mendes-Víctor, L.A. (2001). Contribuição para o estudo da sismicidade da região oeste da Península Ibérica. Universidade de Lisboa, Instituto geofísico do Infante D. Luís, Lisboa, 67 pp.

Masdeu, J.F. de (1793). Historia crítica de España y de la cultura española. Libro 1, Tomo 12, Madrid, 442 pp.

Mezcua Rodríguez, J. \& Martínez Solares, J.M. (1983). Sismicidad del Área Ibero-Mogrebí. Publicación 203, Instituto Geográfico Nacional, Madrid, 303 pp.

Mezcua, J.; Rueda, J. \& García Blanco, R.M. (2013). Iberian Peninsula historical seismicity revisited: An intensity data bank. Seismological Research Letters, 84 (1): 9-18. https://doi.org/10.1785/0220120097

Mezeray, F.E. de (1685). Histoire de France, depuis Faramond jusqu'au règne de Louis le Juste: Enrichie, de plusieurs belles \& rares antiquitéz, \& de la vie des reynes. Des portraits au naturel des rois, des reines, \& des dauphins, tiréz de leurs chartes, effigies, \& autres anciens originaux. Et d'un recueil des médailles qui ont esté fabriquées sous chaque règne; \& de leur explication servant d'éclaircissement à l'histoire. Tomo II, Paris.

MGH - Monumenta Germanier Historica (2018). Annales aevi Suevici, 16. http://www.mgh.de/

Michetti, A.M.; Esposito, E.; Guerrieri, L.; Porfido, S.; Serva, L.; Tatevossian, R.; Vittori, E.; Audemard, F.; Azuma, T.; Clague, J.; Comerci, V.; Gurpinar, A.; Mc Calpin, J.; Mohammadioun, B.; Morner, N.A.; Ota, Y. \& Roghozin, E. (2007). Intensity Scale ESI 2007. In: Guerrieri L. \& Vittori E. (Eds.): Memorie Descrittive Carta Geologica d'Italia., 74, Servizio Geologico d’Italia - Dipartimento Difesa del Suolo, APAT, Roma, 53 pp.

Milne, J. (1912). Catalogue of destructive earthquakes A.D. 7 to A.D. 1899. British Association for the Advancemente os Science, London, 108 pp.

Monsalvo Antón, J.M. (2014). Historia de la España Medieval. Ediciones Universidad de Salamanca, Salamanca, 383 pp.

Moreira de Mendonça, J.J. (1758). Historia universal dos terremotos que tem havido no mundo, de que ha noticia, desde a sua creaçao até o seculo presente. Lisboa, 272 pp.

Moréri, L. (1753). El gran diccionario Histórico. Tomo VIII, primera parte, París, 534 pp.

Murguía, M. (1888). Galicia, España, sus monumentos y artes, su naturaleza e Historia, Ed. Daniel Cortezo, Barcelona, 1196 pp. 
Musson, R. (1996). Determination of parameters for historical British earthquakes. Annali di Geofisica, 34: 1041-1047.

Musson, R.M.W.; Grünthal, G, \& Stucchi, M. (2010). The comparison of macroseismic intensity scales. Journal of Seismology, 14: 413-428. https://doi.org/10.1007/ s10950-009-9172-0

Nieremberg, J.E. (1643). Curiosa y oculta filosofía, primera y segunda parte de las maravillas de la naturaleza, examinadas en varias queftiones naturales. Madrid, 438 pp.

Patricio, A. (1739). Historia das antiguidades de Evora, primeira parte repartida em dez libros, once de relataõ as cousas, que acontecêraõ em Evora até ser tomada aos Mouros por Giraldo, no tempo Del-Rey Dom Affonço Henriquez. Évora.

Perrey, A. (1847). Sur les tremblements de terre de la Péninsule Ibérique. En: Annales des Sciences Physiques et Naturelles, d et d'Industrie (Barret, Ed), Société royale d'agriculture, histoire naturelle et arts utiles de Lyon, Tomo 10, Lyon, 461-514.

Quadrado, J.M. (1855). Recuerdos y bellezas de España: Asturias y León. Madrid, 460 pp.

Rajendran, C.P.; Rajendran, K.; Sanwal, J. \& Sandiford, M. (2013). Archaeological and historical database on the medieval earthquakes of the central Himalaya, ambiguities and inferences. Seismol. Res. Lett., 84 (6): 1098-1108. https://doi.org/10.1785/0220130077

Real Academia Española (1726-1739). Diccionario de Autoridades. http://web.frl.es/DA.html

Rey Pastor, A. (1927). Traits sismiques de la Peninsule Ibérique. Instituto Geográfico y Catastral, Madrid, 87 pp.

Ríos Saloma, M.F. (2011). La Reconquista: una construcción historiográfica (siglos XVI-XIX). Marcial Pons Historia, Madrid, 352 pp.

Rolfe, J.C. (1913). The lives of the twelve caesars. Suetonio - Suetonius Tranquilus - (121 d.C.) De vita Caesarum, 211 pp.

Ruibal Rodríguez, A. (2014). La orden de Santiago en el norte de España. V Congreso Nacional sobre la cultura en Andalucía, Serie cuadernos de Estepa, 3: 57-88.

Sánchez, J.J \& Maldonado, R.F. (2016). Aplication of the ESI-2007 Scale to two large Earthquakes: South Island, Nueva Zeland (2010 Mw 7.1) and Tohoku, Japan (2011 Mw 9.0). Bulletin of the Seismological Society of America, 106 (3): 1151-1161. https://doi. org/10.1785/0120150188

Sánchez-Navarro Neumann, M.M. (1921). Lista de los terremotos más notables sentidos en la Península Ibérica desde los tiempos más remotos, hasta 1917, inclusive, con ensayo de agrupación en regiones y períodos sísmicos. En: La estación sismológica y el Observatorio Astronómico y Meteorológico de Cartuja (Granada). Imprenta Granadina Ros, Granada, 11-65.
Sandoval, F.P. de (1614). Historia del Emperador Carlos V, Rey de España. Pamplona, Tomo II, Libro quinto, Cap. XL.

Santa María, F. de (1744). Anno historico, Diario portuguez, noticia abreviada de pessoas grandes, e cousas notaveis de Portugal... offerecido a el rey D. Joaõ V... por Lourenço Justiniano da Annunciaçaõ. Lisboa, 252 pp.

Senos, M.L \& Carrilho, F. (2003). Sismicidade de Portugal Continental. Física de la Tierra, 15: 93-110.

Serva, L.; Vittori, E.; Comerci, V.; Esposito, E.; Guerrieri, L.; Michetti, A.M.; Mohammadioun, B.; Mohammadioun, G.C.; Porfido, S. \& Tatevossian, R.E. (2016). Earthquake hazard and the Environmental Seismic Intensity (ESI) Scale. Pure and Applied Geophysics, 173 (5): 1479-1515. https://doi.org/10.1007/ s00024-015-1177-8

Seyfart, J.F. (1756). Algemeine Geschichte der Erdbeben. Frankfurt y Leipzig, 394 pp.

Silva-Barroso, P.G.; Rodríguez-Pascua, M.A.; GinerRobles, J.L.; Pérez-López, R.; Lario-Gómez, J.; Perucha-Atienza, M.A.; Bardají-Azcárate, T.; Huerta-Hurtado, P.; Roquero García-Casal, E. \& Bautista-Davila, M.B. (2014). Catálogo de los efectos geológicos de los terremotos en España. Instituto Geológico y Minero de España y Asociación Española para el Estudio del Cuaternario, Madrid, 362 pp.

Sousa Moreira, V.J. de (1991). Sismicidade Histórica de Portugal Continental. Revista do Instituto Nacional de Meteorologia e Geofísica, Lisboa, 79 pp.

Stich, D.; Ammon, C.J. \& Morales, J. (2003) Moment tensor solutions for small and moderate earthquakes in the Ibero-Maghreb region. Journal of Geophysical Research 108 (B3), 2148. https://doi. org/10.1029/2002JB002057

Taboada Leal, N. (1840). Descripción topográfico-histórica de la ciudad de Vigo, su ría y alrededores: con una noticia biográfica de varios hombres ilustres hijos del país. Imprenta de la Viuda é Hijos de Compañel, Santiago, 230 pp.

Terremotos em Portugal (19 de Janeiro de 1923). Voz da Fátima, Número 4, p. 3.

Themudo Barata, M.R.; Braga, L.; Noronha Wagner, M.; Guerra, B.; Felix Alvez, J. \& Neto, J. (1988). Sismicidade de Portugal. Estudo da documentação dos séculos XVII e XVIII. Gabinete de Protecção e Segurança Nuclear, Lisboa, 2, 336 pp.

Udías, A. (2015). Historical Earthquakes (before 1755) of the Iberian Peninsula in Early Catalogs. Seismological Research Letters, 86(3): 999-1005. https://doi. org/10.1785/0220140200

Udías, A. (2017). Terremotos de la Península Ibérica antes de 1900 en los catálogos sísmicos. Física de la Tierra, 29: 11-27. https://doi.org/10.5209/FITE.57186

UGR-Universidad de Granada (2018). Conversión dinámica. www.ugr.es/ eaznar/conversorFecha.htm 
Vicente, G. de; Cloetingh, S.; Muñoz-Martín, A.; Olaiz, A.; Stich, D.; Vegas, R.; Galindo-Zaldívar, J. \& Fernández-Lozano, J. (2008). Inversion of moment tensor focal mechanisms for active stresses around the microcontinent Iberia: Tectonic implications. Tectonics, 27: 1009. https://doi. org/10.1029/2006TC002093

Villamor P.; Capote R.; Stirling M.W.; Tsige M.; Berryman K.R.; Martínez-Díaz J.J. \& MartínGonzález F. (2012). Contribution of active faults in the intraplate area of Iberia to seismic hazard: The Alentejo-Plasencia Fault. Journal of Iberian Geology, 38 (1):85-111. https://doi.org/10.5209/rev_ JIGE.2012.v38.n1.39207

Villa Valdés, A. (2002). Sobre la secuencia cronoestratigráfica de los castros asturianos (siglos VIII a.C. II d.C.). Trabajos de prehistoria, 59(2): 149-162. https://doi.org/10.3989/tp.2002.v59.i2.203
Villa Valdés, A. (2009). Museo castro de Chao Samartin. Consejería de Cultura y Turismo del Principado de Asturias y Asociación de Amigos del Parque Histórico del Navia, Asturias, 560 pp.

Villar Vidal, J.A. (1993). Livius, T. (siglo I a.C.) Ab Urbe Condita, Liber XXII. [Edición en español: Tito Livio (1993): Historia de Roma desde su fundación, Libros XXI-XXV. Traducción y notas de José Antonio Villar Vidal, Ed. Gredos, Madrid, 488 pp.

Von Hoff, K.E.A. (1824). Geschichte der durch Überlieferung nachgewiesenen natürlichen Veränderungen der Erdoberfläche. Gotha, Tomo 2, 560 pp.

Von Hoff, K.E.A. (1840). Geschichte der durch Überlieferung nachgewiesenen natürlichen Veränderungen der Erdoberfläche. Theil: Chronik der Erdbeben und Vulcan-Ausbrüche, vom Jahr 2460 vor, bis 1759 unserer Zeitrechnung. Gotha, Tomo 4, 471 pp. 